\title{
On the Identification of Fiscal Policy Behavior
}

\author{
Bing $\mathrm{Li}^{*}$ \\ Department of Economics \\ Indiana University
}

March 30, 2009

\begin{abstract}
In the current literature, fiscal policy is usually characterized by a singleequation rule, in which primary surplus is generally defined as a function of lagged government debt, other controlled variables and a fiscal policy shock. To apply Ordinary Least Squares (OLS) method on the single-equation rule has been one of the common approaches to identify fiscal policy behavior. From the rational expectations general equilibrium perspective, this paper illustrates that lagged government debt is generally endogenous and the OLS approach suffers from simultaneity bias. Consequently, the OLS-based identification of fiscal policy behavior is unreliable. As a solution, we apply the Generalized Method of Moments (GMM) for estimation and inference. Monte Carlo experiments demonstrate that GMM provides more reliable results than OLS in terms of accuracy of the estimator, size and power. In short, people should be cautious of the existing OLS-based identification results of fiscal policy behavior and the empirical researchers should not consider OLS regression as a reliable tool when trying to identify fiscal policy behavior in the future.
\end{abstract}

Keywords: Fiscal Policy Rule, Non-Ricardian, Ricardian, Simultaneity Bias, OLS, GMM, Size, Power

JEL Classficiation: C12, C13, E63

${ }^{*}$ Contact Information: Department of Economics, Indiana University, Wylie Hall 344, $100 \mathrm{~S}$. Woodlawn, Bloomington, IN 47405. Phone Number:(812)855-5308. Email: bl1@indiana.edu. I am especially grateful to Eric Leeper, my advisor, for his valuable advice, guidance and encouragement during the formation of this paper. I am also grateful to Juan Carlos Escanciano, Jüergen von Hagen, Todd Walker, Rusty Tchernis, and Pei Pei for their valuable comments and suggestions. This version is incomplete. All remaining errors are my own. 


\section{Introduction}

In the current literature, fiscal policy is usually characterized by a single-equation rule $^{1}$, i.e. fiscal reaction function, just as the monetary policy being characterized by a Taylor-type interest rate rule. Generally, the fiscal policy rule defines primary surplus as a function of lagged government debt, other controlled variables such as the output gap or GDP growth, and a fiscal policy shock. Since the main interest of this paper lies in the lagged government debt, we suppress the output gap or GDP growth to simplify the analysis and specify the fiscal policy rule as the following

$$
\tilde{\tau}_{t}=\gamma_{0}+\gamma \tilde{b}_{t-1}+\tilde{\psi}_{t}
$$

where $\tau_{t}$ is real primary surplus, $b_{t-1}$ is lagged real government debt and $\psi_{t}$ is fiscal policy shock. Variables with " " are measured in logarithm.

In empirical work, applying Ordinary Least Squares (OLS) method on the fiscal policy rule similar to (1) has been one of the common approaches to identify fiscal policy behavior, such as Bohn (1998) with the U.S. data. For those papers running policy rule regression, the fiscal rule is generally treated as a structural equation and behavioral interpretation is usually attached to the regression results. For instance, Bohn (1998) interprets the OLS estimator of the coefficient of government debt as the indicator of fiscal sustainability ${ }^{2}$.

To guarantee the validity of the results, the papers applying OLS regression on the fiscal policy rule always assume, implicitly or not, that the lagged government debt is exogenous relative to the fiscal policy shock, which, in terms of (1), implies that $\tilde{b}_{t-1}$ is uncorrelated with $\tilde{\psi}_{t}$. This assumption seems "justifiable" at the first glance because $\tilde{b}_{t-1}$ is predetermined relative to $\tilde{\psi}_{t}$. Unfortunately, macroeconomic theory indicates that $\tilde{b}_{t-1}$ in $(1)$ is generally endogenous so that $\tilde{b}_{t-1}$ is correlated with $\tilde{\psi}_{t}^{3}$ and the

\footnotetext{
${ }^{1}$ There is an extensive literature that specifies and estimates single-equation fiscal policy rule, to name a few, such as Bohn (1998), Galí and Perotti (2003) and Auerbach (2003).

${ }^{2}$ For those papers including output gap or GDP growth in the fiscal policy rule, the coefficient of output gap or GDP growth is usually interpreted as the indicator of fiscal authority's stance on economic stabilization.

${ }^{3}$ For the papers including output gap or GDP growth in the fiscal policy rule, such as Galí and Perotti (2003), instrumental variables (IV) estimation is applied to correct for the endogeneity
} 
OLS regression is invalid. More specifically, according to the rational expectations hypothesis, the economy is forward-looking in nature and the general equilibrium can be summarized by a system of simultaneous equations. Based on the system, the endogeneity of $\tilde{b}_{t-1}$ relative to $\tilde{\psi}_{t}$ becomes obvious by looking at the intertemporal government budget constraint (2), which always holds as an equilibrium condition regardless of the fiscal policy rule in place

$$
\text { Gov.Debt }=\text { Expected Present Value of (Future Surpluses + Future Seigniorage) }
$$

That is to say, in equilibrium, not only (1) but also (2) links the government debt to the future primary surpluses. If the fiscal policy rule (1) is isolated from the whole system, important information from other aspects of the economy, especially (2), will be missing and the policy rule regression will suffer from simultaneity bias, which induces inconsistency in the OLS estimator of $\gamma$, i.e. $\hat{\gamma}_{O L S}{ }^{4}$. As a consequence, $\hat{\gamma}_{O L S}$ is not accurate and even worse, the OLS-based identification of fiscal policy behavior is unreliable. This methodological problem has been recognized in the literature for a long time ${ }^{5}$. But there has not been much work done to systematically illustrate the nature and the severity of the problem by closely connecting with the macroeconomic theory. Our paper tries to shed some light in that direction. Since the problem is best illustrated in a specific model environment, we adopt a simple Dynamic Stochastic General Equilibrium (DSGE) model, which is similar to Leeper (1991) and (2005), as the data-generating process (DGP).

The first contribution of this paper is to investigate the simultaneity bias problem analytically. From the simple analytical example, we illustrate that if an econometrician runs OLS regression on (1) using equilibrium data, which is generated by the underlying DGP, the econometric model (1) is misspecified and $\hat{\gamma}_{O L S}$ is inconsistent, which makes the structural interpretation attached to $\hat{\gamma}_{O L S}$ misleading and the identification of fiscal policy behavior unreliable. To help understand the nature of the

of the output gap. However, the exogeneity assumption of the lagged government debt is generally preserved, which means that the problem examined in this paper also matters in that line of research.

${ }^{4}$ There are a few exceptions where $\hat{\gamma}_{O L S}$ is consistent, which will be discussed later in the paper.

${ }^{5}$ A non-exhaustive list of papers addressing this issue includes Cochrane (1998), Woodford (1998), (2001) and Davig, Leeper and Chung (2007). 
problem, we provide economic interpretation of the bias. Several results from the analysis of the illustrative model are worth mentioning. First, with serially correlated fiscal policy shock, which is a reasonable assumption consistent with the empirical evidence, the simultaneity bias problem prevails in the parameter space. For example, when the monetary and fiscal policy combination is non-Ricardian ${ }^{6}$ in the DGP, the bias can be negative, positive or in some rare cases zero; when the policy combination is Ricardian in the DGP, the bias is always negative. Second, regardless of the underlying DGP, OLS estimator of the fiscal policy rule is inaccurate and the corresponding identification of fiscal policy behavior is unreliable. Third, monetary and fiscal policy interaction matters for the identification of fiscal policy behavior. For example, with a non-Ricardian policy combination in the DGP, as monetary policy pays less attention to inflation, $\hat{\gamma}_{O L S}$ would be biased up more so that the econometrician would mistakenly regard the policy combination in the DGP as Ricardian with higher probability.

The second contribution of the paper is to correct for the simultaneity bias by applying the Generalized Method of Moments (GMM) for estimation and inference, which provides more reliable results. In order to illustrate the distinct performance of OLS and GMM, we calibrate the model to the U.S. data and carry out Monte Carlo experiments. It turns out that over the whole parameter space we are interested in, GMM performs better than OLS in terms of accuracy of estimator, size and power.

The rest of the paper is organized as follows. In section 2, we specify and solve the simple DSGE model. We also derive the state-space representation of the model, which is used to generate artificial data in the Monte Carlo experiments. In section 3, we derive the analytical form of the simultaneity bias and provide economic interpretation of the bias. Section 4 specifies the basic GMM setup. Section 5 reports the results of the Monte Carlo experiments. Section 6 concludes.

\footnotetext{
${ }^{6}$ According to Leeper (1991)'s terminology, monetary policy is passive when interest rate responds to inflation less than one-for-one and active when the response is more than one-for-one; loosely speaking, fiscal policy is passive when tax responds outstanding government debt strongly and active otherwise. In the literature of the fiscal theory of price level, an equilibrium is defined as nonRicardian when monetary policy is passive and fiscal policy is active. On the contrary, when monetary policy is active and fiscal policy is passive, the equilibrium is defined as Ricardian.
} 


\section{The Illustrative Model}

\subsection{Model Setup}

This is an endowment economy model which is similar to Leeper (1991) and (2005). In the model, there is an infinitely lived representative agent who chooses sequences $\left\{c_{t}, M_{t}, B_{t}\right\}_{t=0}^{\infty}$ to solve the household problem:

$$
\max E_{0} \sum_{t=0}^{\infty} \beta^{t}\left[\ln \left(c_{t}\right)+\delta \ln \left(M_{t} / P_{t}\right)\right]
$$

subject to the flow budget constraint

$$
c_{t}+\frac{M_{t}+B_{t}}{P_{t}}+\tau_{t}=y+\frac{M_{t-1}+R_{t-1} B_{t-1}}{P_{t}}
$$

taking the initial liabilities $M_{-1}+R_{-1} B_{-1}>0$ and sequences $\left\{y, \tau_{t}, R_{t}, P_{t}\right\}_{t=0}^{\infty}$ as given. In $(3)$ and $(4), \beta \in(0,1)$ is the discount factor, $\delta \in(0, \infty)$ is the weight on real money balance in the utility function, $c_{t}$ is the real consumption, $M_{t}$ is the nominal money balance, $B_{t}$ is the nominal one-period government debt with gross nominal interest rate $R_{t}, P_{t}$ the is price level, $y$ is the constant endowment and $\tau_{t}$ is the lump-sum taxes (if positive) or transfers (if negative).

There is a government with policy sequences $\left\{M_{t}, B_{t}, \tau_{t}\right\}_{t=0}^{\infty}$ subject to the government budget constraint

$$
\frac{M_{t}+B_{t}}{P_{t}}+\tau_{t}=g_{t}+\frac{M_{t-1}+R_{t-1} B_{t-1}}{P_{t}}
$$

where $g_{t}$ is the government spending.

The resource constraint is

$$
c_{t}+g_{t}=y
$$

For simplicity, we assume $g_{t}=0$ for all $t$. So (6) reduces to $c_{t}=c=y$, which is the goods market clearing condition.

We obtain the following Fisher and money-demand relations from the standard 
first-order necessary conditions and the resource constraint (6):

$$
\begin{aligned}
\frac{1}{R_{t}} & =\beta E_{t}\left[\frac{1}{\pi_{t+1}}\right] \\
m_{t} & =\delta c\left[\frac{R_{t}}{R_{t}-1}\right]
\end{aligned}
$$

where $\pi_{t+1} \equiv P_{t+1} / P_{t}$ and $m_{t} \equiv M_{t} / P_{t}$ are the inflation rate and the real money balance, respectively.

The model is closed by specifying monetary and fiscal policies, which are characterized by simple rules that determine their corresponding policy instruments. Monetary policy is described by the Taylor-type interest rate rule

$$
R_{t}=e^{\alpha_{0}} \pi_{t}^{\alpha} \theta_{t}
$$

and fiscal policy is described by the tax rule

$$
\tau_{t}=e^{\gamma_{0}} b_{t-1}^{\gamma} \psi_{t}
$$

where $b_{t-1} \equiv B_{t-1} / P_{t-1}$ is the real government debt. We assume that the exogenous monetary and fiscal policy shocks $\theta_{t}$ and $\psi_{t}$ have unit means and their logarithms follow $\mathrm{AR}(1)$ processes

$$
\begin{aligned}
\ln \left(\theta_{t}\right) & =\theta_{0}+\rho_{\theta} \ln \left(\theta_{t-1}\right)+\varepsilon_{\theta_{t}} \\
\ln \left(\psi_{t}\right) & =\psi_{0}+\rho_{\psi} \ln \left(\psi_{t-1}\right)+\varepsilon_{\psi_{t}}
\end{aligned}
$$

where $\theta_{0}$ and $\psi_{0}$ are drift terms. $\left|\rho_{\theta}\right|<1$ and $\left|\rho_{\psi}\right|<1$ are assumed for stationarity. The innovations to both policy shocks, $\varepsilon_{\theta_{t}}$ and $\varepsilon_{\psi_{t}}$, are assumed to be independent and identically-distributed (i.i.d.) ${ }^{7}$ random variables with zero means and bounded support. Their standard deviations are $\sigma_{\theta}$ and $\sigma_{\psi}$, respectively.

\footnotetext{
${ }^{7}$ Here we make a strong assumption on $\varepsilon_{\theta_{t}}$ and $\varepsilon_{\psi_{t}}$ to separate effects of different shocks in a clear manner, which makes the illustration more transparent. To allow for nonzero cross-correlation between different policy shock innovations, which is more realistic, makes the derivation more cumbersome, but would not change the main results of the paper significantly.
} 


\subsection{Model Solution}

The general equilibrium of the model is fully characterized by (5), (7)-(12). To solve the model, we firstly log-linearize the equilibrium conditions around the deterministic steady state, as shown in Appendix A. The linearized system is organized in the standard matrix form

$$
\Gamma_{0} Y_{t+1}=\Gamma_{1} Y_{t}+\Pi \eta_{t+1}+\Psi \varepsilon_{t+1}
$$

where $Y_{t+1}=\left[\hat{\pi}_{t+1}, \hat{b}_{t+1}, \hat{\theta}_{t+1}, \hat{\psi}_{t+1}\right]^{\prime}, \varepsilon_{t+1}=\left[\varepsilon_{\theta_{t+1}}, \varepsilon_{\psi_{t+1}}\right]^{\prime}$. Any variable $\hat{x}_{t}$ denotes $\log$ deviation of $x_{t}$ from its corresponding steady state value $x$, i.e. $\hat{x}_{t} \equiv \ln \left(x_{t}\right)-\ln (x)$. We also define the one-period-ahead endogenous forecasting error $\eta_{t+1} \equiv \hat{\pi}_{t+1}-E_{t} \hat{\pi}_{t+1}$.

Since $\Gamma_{0}$ is invertible, (13) can be expressed as

$$
Y_{t+1}=\Gamma_{1}^{*} Y_{t}+\Pi^{*} \eta_{t+1}+\Psi^{*} \varepsilon_{t+1}
$$

where $\Gamma_{1}^{*}=\Gamma_{0}^{-1} \Gamma_{1}, \Pi^{*}=\Gamma_{0}^{-1} \Pi$ and $\Psi^{*}=\Gamma_{0}^{-1} \Psi$. Determinacy of bounded equilibrium ${ }^{8}$ of the model hinges on the eigenvalues of $\Gamma_{1}^{*}$, which are $\left[\alpha, \beta^{-1}-\gamma\left(\beta^{-1}-1\right), \rho_{\theta}, \rho_{\psi}\right]$. According to Leeper (1991) and (2005), we are able to characterize four different regions in the first quadrant of $(\alpha, \gamma)$ space $^{9}$, two of which indicate determinacy: (1) When $\alpha<1$ and $\gamma<1$, monetary policy is passive and fiscal policy is active. The equilibrium is determinate and non-Ricardian; (2) When $\alpha>1$ and $\gamma>1$, monetary policy is active and fiscal policy is passive. The equilibrium is determinate and Ricardian; (3) When $\alpha<1$ and $\gamma>1$, monetary and fiscal policies are both passive and bounded equilibrium is indeterminate; (4) When $\alpha>1$ and $\gamma<1$, monetary and fiscal policies are both active and no bounded equilibrium exists. Figure 1 demonstrates these four regions, where determinacy regions are superimposed by red lines.

In Appendix A, we apply a Jordan decomposition to obtain the analytical solution of the model. If the bounded equilibrium is determinate, the following conditions that

\footnotetext{
${ }^{8}$ In this paper, we are only interested in the determinate equilibrium, which is bounded because we have assumed that random variables $\varepsilon_{\theta_{t}}$ and $\varepsilon_{\psi_{t}}$ have bounded support.

${ }^{9} \mathrm{In}$ fact, it is the absolute values of the eigenvalues that matter for the determinacy. However, we only focus on the economically interesting regions in the paper, i.e. the first quadrant of $(\alpha, \gamma)$ space.
} 
suppress the unstable root of the dynamic system must hold for all $t$ :

$$
\begin{aligned}
& P^{i \cdot} Y_{t}=0 \\
& P^{i \cdot} \Pi^{*} \eta_{t+1}+P^{i \cdot} \Psi^{*} \varepsilon_{t+1}=0
\end{aligned}
$$

where, according to Appendix $\mathrm{A}, P^{i}$ is the $i$ th row of $P^{-1}$ and $i$ is the index denoting the unstable eigenvalue in $\Lambda . P^{-1}$ and $\Lambda$, which are defined in Appendix $\mathrm{A}$, are standard matrices appearing in the Jordan decompostion. In this model context, $i=1$ is corresponding to Ricardian equilibrium and 2 is corresponding to non-Ricardian equilibrium. In both cases, $\eta_{t+1}$ is uniquely determined by (16). If the bounded equilibrium is indeterminate, there is no unique mapping between $\eta_{t+1}$ and $\varepsilon_{t+1}$. For the rest of the paper, we will focus on the determinacy regions. The solution procedure outlined here will be used later to derive the analytical form of the simultaneity bias associated with the OLS estimator of the fiscal policy rule.

\subsection{State-Space Representation}

The state equation (17), which is also the numerical solution of the model, is obtained by applying gensys algorithm ${ }^{10}$, which is based on Sims' (2001).

$$
Y_{t+1}=G_{1} Y_{t}+M \varepsilon_{t+1}
$$

The matrices $G_{1}$ and $M$ in (17) are outputs from gensys algorithm. Since both the model and the data are quarterly, we define the observation equation as

$$
\left[\begin{array}{c}
\hat{\pi}_{t+1}^{o} \\
\hat{b}_{t+1}^{o}
\end{array}\right]=\left[\begin{array}{llll}
1 & 0 & 0 & 0 \\
0 & 1 & 0 & 0
\end{array}\right]\left[\begin{array}{c}
\hat{\pi}_{t+1} \\
\hat{b}_{t+1} \\
\hat{\theta}_{t+1} \\
\hat{\psi}_{t+1}
\end{array}\right]
$$

where superscript "o" denotes observable variables.

Based on the state-space representation (17) and (18), we are able to simulate artificial data, which is used by the econometrician in the Monte Carlo experiments.

\footnotetext{
${ }^{10}$ gensys algorithm can be downloaded from Chris Sims' homepage.
} 


\section{OLS Regression: An Analytical Investigation}

Now we treat the DSGE model specified in the previous section as the underlying DGP and suppose an econometrician tries to identify fiscal policy behavior. We assume the data the econometrician uses are measured in logarithms, which are denoted by $\tilde{x}_{t} \equiv \ln \left(x_{t}\right)$ for any variable $x_{t}$. Because the observable variables are equivalent to the model variables according to (18), we will suppress the superscript "o" henceforth.

Taking log on both sides of (10), the fiscal policy rule is in the following form

$$
\tilde{\tau}_{t}=\gamma_{0}+\gamma \tilde{b}_{t-1}+\tilde{\psi}_{t}
$$

To simplify the analysis for the time being, we assume that the econometrician knew the exact form of the fiscal policy rule (19). From the econometrician's perspective, $\tilde{b}_{t-1}$ is predetermined relative to $\tilde{\psi}_{t}$. Therefore, an OLS regression on the structural equation (19) seems to be "justified". Because of the "validity" of OLS regression, the econometrician naturally attaches behavioral interpretation to the OLS estimator of $\gamma$. The econometrician then identifies fiscal policy behavior based on $\hat{\gamma}_{O L S}$. Unfortunately, as will be shown in this section, the OLS regression is not valid, which is not recognized by the econometrician. The subtlety of the failure of OLS regression lies in the fact that the econometric model is misspecified, which is due to the isolation of the fiscal policy rule from the whole system of structural equations ${ }^{11}$.

Mathematically, Appendix B shows that the probability limit of $\hat{\gamma}_{O L S}$ is

$$
\operatorname{plim} \hat{\gamma}_{O L S}=\gamma+\frac{\operatorname{cov}\left(\tilde{b}_{t-1}, \tilde{\psi}_{t}\right)}{\operatorname{var}\left(\tilde{b}_{t-1}\right)}
$$

where $\operatorname{cov}(\cdot, \cdot)$ and $\operatorname{var}(\cdot)$ are covariance and variance operators, respectively. It is clear in (20) that the probability limit of $\hat{\gamma}_{O L S}$ contains an additional term besides $\gamma$. Later we will illustrate that the additional term is nonzero everywhere in the parameter space, with exceptions only in some special cases. As mentioned earlier, when running OLS regression on (19), the econometrician isolates (19) from the system of structural

\footnotetext{
${ }^{11}$ Here we only consider one type of misspecification, i.e. isolation of one structural equation from the system. In practice, it is possible that the functional form of the fiscal policy rule is also misspecified, which will be considered in the future work.
} 
equations implied by the general equilibrium. So $\hat{\gamma}_{O L S}$ is intrinsically subject to simultaneity bias, which, asymptotically, is captured by the term $\operatorname{cov}\left(\tilde{b}_{t-1}, \tilde{\psi}_{t}\right) / \operatorname{var}\left(\tilde{b}_{t-1}\right)$ in $(20)$.

In the next four subsections, we investigate the simultaneity bias through four cases. DGPs of the first three cases are characterized by non-Ricardian policy combination and that of the last case is characterized by Ricardian policy combination. For each case, we provide economic interpretation of the bias, which helps understand the nature of the problem. To make the economic interpretation straightforward, we iterate (5) forward over $B / P$ and take expectation conditional on the information set at period $t-1$. Then we get the intertemporal government budget constraint:

$$
\frac{B_{t-1}}{P_{t-1}}=E_{t-1} \sum_{i=0}^{\infty}\left(\prod_{j=0}^{i} \pi_{t+j} R_{t+j-1}^{-1}\right)\left[\tau_{t+i}+\frac{M_{t+i}-M_{t+i-1}}{P_{t+i}}\right]
$$

where the transversality condition for government debt has been imposed. The intertemporal government budget constraint (21) is a general equilibrium condition that always holds in equilibrium regardless of the policy combination in place. This condition tells us that, in equilibrium, real government debt is always equal to the sum of expected present value of future surpluses and seigniorage revenues.

\subsection{Case I (Non-Ricardian): $\alpha=\gamma=\rho_{\theta}=\rho_{\psi}=0$}

In this case, nominal interest rate is pegged; primary surplus is exogenous; both the monetary and the fiscal policy shocks are serially uncorrelated. The solution is greatly simplified under these assumptions. First, condition (15) reduces to

$$
\tilde{b}_{t}=\ln (b)+\beta\left(\varphi_{1}+\varphi_{4}\right) \varepsilon_{\theta_{t}}
$$

Since $\tilde{\psi}_{t}$ is i.i.d., we have $\tilde{\psi}_{t}=\varepsilon_{\psi_{t}}$. Then the covariance term in (20) becomes

$$
\operatorname{cov}\left(\tilde{b}_{t-1}, \tilde{\psi}_{t}\right)=\operatorname{cov}\left[\ln (b)+\beta\left(\varphi_{1}+\varphi_{4}\right) \varepsilon_{\theta_{t-1}}, \varepsilon_{\psi_{t}}\right]=0
$$

where the covariance is 0 because we have assumed $\varepsilon_{\theta}$ and $\varepsilon_{\psi}$ are both i.i.d., which indicates zero correlation between each other for all leads and lags. Consequently, 
$\operatorname{plim} \hat{\gamma}_{O L S}=\gamma$ and the OLS estimator of $\gamma$ is free of simultaneity bias, which guarantees reliable identification of fiscal policy behavior. However, to assume fiscal policy shock being serially uncorrelated is not consistent with the empirical evidence.

\subsection{Case II (Non-Ricardian): $\alpha=\gamma=\rho_{\theta}=0, \rho_{\psi} \neq 0$}

In this case, we keep the assumptions of case I except that fiscal policy shock $\tilde{\psi}_{t}$ becomes serially correlated. First, condition (15) reduces to

$$
\begin{aligned}
\tilde{b}_{t} & =\ln (b)+\beta\left(\varphi_{1}+\varphi_{4}\right) \tilde{\theta}_{t}+\left[\frac{\left(\beta^{-1}-1\right) \rho_{\psi}}{\beta^{-1}-\rho_{\psi}}\right] \tilde{\psi}_{t} \\
& =\ln (b)+\beta\left(\varphi_{1}+\varphi_{4}\right) \varepsilon_{\theta_{t}}+\left[\frac{\left(\beta^{-1}-1\right) \rho_{\psi}}{\beta^{-1}-\rho_{\psi}}\right] \frac{\varepsilon_{\psi_{t}}}{\left(1-\rho_{\psi} L\right)}
\end{aligned}
$$

where we rewrite $\tilde{\psi}_{t}$ as $\varepsilon_{\psi_{t}} /\left(1-\rho_{\psi} L\right)$ by introducing the lag operator. Then the covariance term in (20) becomes

$$
\begin{aligned}
\operatorname{cov}\left(\tilde{b}_{t-1}, \tilde{\psi}_{t}\right) & =\operatorname{cov}\left[\ln (b)+\beta\left(\varphi_{1}+\varphi_{4}\right) \varepsilon_{\theta_{t}}+\frac{\left(\beta^{-1}-1\right) \rho_{\psi}}{\beta^{-1}-\rho_{\psi}} \frac{\varepsilon_{\psi_{t-1}}}{\left(1-\rho_{\psi} L\right)}, \frac{\varepsilon_{\psi_{t}}}{\left(1-\rho_{\psi} L\right)}\right] \\
& =\left[\frac{\left(\beta^{-1}-1\right) \rho_{\psi}}{\beta^{-1}-\rho_{\psi}}\right] \operatorname{cov}\left[\frac{\varepsilon_{\psi_{t-1}}}{\left(1-\rho_{\psi} L\right)}, \frac{\varepsilon_{\psi_{t}}}{\left(1-\rho_{\psi} L\right)}\right] \\
& =\left[\frac{\left(\beta^{-1}-1\right) \sigma_{\psi}^{2}}{\beta^{-1}-\rho_{\psi}}\right] \sum_{i=1}^{\infty} \rho_{\psi}^{2 i} \\
& =\frac{\left(\beta^{-1}-1\right) \rho_{\psi}^{2} \sigma_{\psi}^{2}}{\left(\beta^{-1}-\rho_{\psi}\right)\left(1-\rho_{\psi}^{2}\right)}>0
\end{aligned}
$$

It is obvious that the covariance is always positive, which implies that the simultaneity bias is always positive, i.e. plim $\hat{\gamma}_{O L S}>\gamma$. The OLS estimator of $\gamma$ is inconsistent. Even though $\gamma=0$ by assumption, asymptotically, $\hat{\gamma}_{O L S}$ may be significantly large in some cases so that the econometrician may mistakenly identify the underlying fiscal policy as passive and the equilibrium as Ricardian. In small samples, this also has negative effect on the econometrician's inference, which will be illustrated in the Monte Carlo experiments.

To get more economic insight into the positive bias, let us suppose in period $t-1$, there is a surprise tax cut, i.e. $\varepsilon_{\psi_{t-1}}<0$. Since $\rho_{\psi} \neq 0$ in this case, a tax cut at period 
$t-1$ projects lower path of future taxes $\tau_{t+i}$, for $i \geq 0$. In this endowment economy, the surprise tax cut has no impact on the expected discount factor in (21). Therefore, expected future surpluses on the right-hand side (RHS) of (21) get lower, which is called the expected surplus effect. Besides that, lower expected path of future taxes makes people feel wealthier, i.e. the wealth effect, which immediately raises demand for goods. Since the supply of goods is equal to the constant endowment, higher demand leads to higher inflation. However, because $\alpha=0$, nominal interest rate is pegged and does not respond to higher inflation. So expected future inflation and seigniorage revenues are not affected. In summary, the RHS of (21) gets lower due to the expected surplus effect, which makes $B_{t-1} / P_{t-1}$ and $\tilde{b}_{t-1}$ lower. Because $\tilde{\psi}_{t}$ is on a lower path, it tends to be lower than before. As a result, $\tilde{b}_{t-1}$ and $\tilde{\psi}_{t}$ are positively correlated, which is consistent with the positive covariance in (25).

\subsection{Case III (Non-Ricardian): $\gamma=\rho_{\theta}=0, \alpha \neq 0, \rho_{\psi} \neq 0$}

In this case, we keep the assumptions of case II except that the monetary authority starts to respond to inflation when setting the nominal interest rate. In general form, condition (15) is

$$
a_{21} \hat{\pi}_{t}+\hat{b}_{t}+a_{23} \hat{\theta}_{t}+a_{24} \hat{\psi}_{t}=0
$$

where $a_{i j}$ is the $i j$ th entry of $P^{-1}$. Derivation of $\operatorname{cov}\left(\tilde{b}_{t-1}, \tilde{\psi}_{t}\right)$ and $\operatorname{var}\left(\tilde{b}_{t-1}\right)$ is shown in Appendix C.

From (53) in Appendix C, it is not obvious to determine the sign of the simultaneity bias. Instead, we evaluate the bias numerically over a grid in the space of $\left(\alpha, \rho_{\psi}\right)$, where both parameters range from 0.01 to 0.99 with increments of 0.01 . We normalize the economy by setting $y=1$. As assumed, $\gamma$ and $\rho_{\theta}$ are both zero. We calibrate the other parameters to match the U.S. data ${ }^{12}$. First, $\beta$ and $\delta$ are calibrated as 0.99 and 0.001 so that the steady state nominal interest rate and normalized real money

\footnotetext{
${ }^{12}$ Since the model implies that output equals consumption, we use personal consumption expenditures as output data, which is from NIPA Table 2.3.5. Data for the nominal interest rate, the nominal monetary base and the inflation rate are from the Federal Reserve Bank of St.Louis, which can be found at http://research.stlouisfed.org/fred2/. Data for the nominal government debt is from the Federal Reserve Bank of Dallas, which can be found at http://www.dallasfed.org/data/data/natdebt.htm.
} 
balance are 1.01 and 0.1 , respectively. Second, $\gamma_{0}$ is implicitly calibrated to match the steady state normalized real government debt 0.8. Finally, at each grid point, $\sigma_{\theta}$ and $\sigma_{\psi}$ are calibrated to match standard deviations of $\hat{\pi}_{t}^{o}$ and $\hat{b}_{t}^{o}$, which are 0.007 and 0.3 , respectively. Here, $\hat{\pi}_{t}^{o}$ and $\hat{b}_{t}^{o}$ are percentage deviations of observed inflation and real government debt from their corresponding long-run averages.

Figure 2 is the plot of the simultaneity bias over the grid, which is calculated based on the analytical form. Conditional on the calibrated parameter values, the bias can be either positive or negative, depending on $\alpha$ and $\rho_{\psi}$. The bias function is continuous at zero, which means that $\rho_{\psi}=0$ is only sufficient but not necessary for zero bias in the non-Ricardian case. Obviously, with highly persistent fiscal policy shocks (e.g. $\rho_{\psi}>0.8$ ) and relatively passive monetary policy (e.g. $\alpha<0.5$ ), the bias is mostly positive and can be very huge. Sometimes, the bias even exceeds 1 , the critical value between active and passive fiscal policies in our model. In such cases, even though $\gamma=0$ by assumption, the econometrician may mistakenly identify the underlying fiscal policy as passive and the equilibrium as Ricardian, which is similar to case II. On the other hand, by keeping $\rho_{\psi}$ at high levels and increasing $\alpha$, the sign of the bias may be reversed, which may also disturb the econometrician's inference.

To get more economic intuition into the bias, let us again suppose in period $t-1$, there is a surprise tax cut, i.e. $\varepsilon_{\psi_{t-1}}<0$. The tax cut at period $t-1$ lowers the expected future surpluses on the RHS of (21), which is the expected surplus effect. Also, lower expected path of future taxes leads to higher inflation at $t-1$ through wealth effect. Since $\alpha \neq 0$, generally $\alpha>0$, higher inflation leads to higher nominal interest rate through the monetary policy rule. According to the Fisher equation, higher interest rate raises expected inflation, which in turn raises expected seigniorage revenues. We call this the expected seigniorage effect. Since the expected discount factor is constant, the net effect of a tax cut on the RHS of (21) depends on the tradeoff between the expected surplus effect and the expected seigniorage effect. Consequently, the correlation between the tax cut and $\tilde{b}_{t-1}$ is ambiguous. Loosely speaking, given $\alpha$, higher $\rho_{\psi}$ implies stronger expected surplus effect, which tends to induce positive correlation; given $\rho_{\psi}$, higher $\alpha$ implies stronger expected seigniorage effect, which tends to induce negative correlation. As a result, the correlation between $\tilde{b}_{t-1}$ and $\tilde{\psi}_{t}$ 
can be either positive or negative, which is displayed in Figure 2.

\subsection{Case IV (Ricardian)}

In this case, monetary policy is active and fiscal policy is passive. Condition (15) reduces to

$$
\tilde{\pi}_{t}=-\frac{1}{\alpha-\rho_{\theta}} \tilde{\theta}_{t}
$$

From condition (16), we can solve for the unique $\eta_{t}$

$$
\eta_{t}=-\frac{1}{\alpha-\rho_{\theta}} \varepsilon_{\theta_{t}}
$$

Since the DGP is characterized by Ricardian equilibrium, the second row of system (51), as shown in Appendix A, is a stable first-order difference equation, from which we can solve for $\tilde{b}_{t}$ as a function of $\varepsilon_{\theta}$ and $\varepsilon_{\psi}$. Eventually, Appendix $\mathrm{C}$ shows that

$$
\operatorname{cov}\left(\tilde{b}_{t-1}, \tilde{\psi}_{t}\right)=-\frac{\rho_{\psi} \sigma_{\psi}^{2}}{\left[1-\left(\beta^{-1}-\gamma\left(\beta^{-1}-1\right)\right) \rho_{\psi}\right]\left(1-\rho_{\psi}^{2}\right)}
$$

which is always negative unless $\rho_{\psi}=0$. This indicates that serially correlated fiscal policy shock is sufficient and necessary for negative simultaneity bias in the case of Ricardian equilibrium. Hence, plim $\hat{\gamma}_{O L S}<\gamma$ and OLS estimator of $\gamma$ is inconsistent. Asymptotically, $\hat{\gamma}_{O L S}$ in some cases may be significantly smaller than $\gamma$ so that the econometrician may mistakenly identify the underlying fiscal policy as active and the equilibrium as non-Ricardian. The effect of the negative bias on the econometrician's inference in small samples will be illustrated in the Monte Carlo experiments.

The economic interpretation underlying the case of Ricardian equilibrium is straightforward. We again suppose in period $t-1$, there is a surprise tax cut, i.e. $\varepsilon_{\psi_{t-1}}<0$. From the solution of $\tilde{b}_{t-1}$, it can be shown that a tax cut at $t-1$ raises $\tilde{b}_{t-1}$ immediately. According to the tax rule, higher $\tilde{b}_{t-1}$ raises lump-sum tax at $t$, which neutralizes the effect of a tax cut to the point that inflation at $t-1$ keeps unchanged. This is the standard result of Ricardian equivalence. On the other hand, a tax cut at $t-1$ reduces $\tilde{\psi}_{t-1}$ and tends to reduce $\tilde{\psi}_{t}$, provided $\rho_{\psi}>0$. So $\tilde{b}_{t-1}$ and $\tilde{\psi}_{t}$ tend to be negatively correlated, which is consistent with the negative covariance (29). 


\subsection{Summary}

From the above four cases, it is clear that the simultaneity bias associated with OLS regression on the fiscal policy rule prevails no matter what the underlying DGP is. This could make identification of true fiscal policy behavior very difficult. With nonRicardian equilibrium in the DGP, on one hand, fiscal policy could be very active, which implies that $\gamma$ could be very small and the link between $\tilde{b}_{t-1}$ and $\tilde{\tau}_{t}$ through the fiscal policy rule could be very weak. On the other hand, correlation between $\tilde{b}_{t-1}$ and $\tilde{\tau}_{t}$ through the equilibrium condition (21) could be very strong. When the econometrician runs OLS regression on the fiscal policy rule using equilibrium data, it is very possible that $\hat{\gamma}_{O L S}$ is significantly large. With Ricardian equilibrium in place, both fiscal policy rule and (21) imply relatively strong correlation between $\tilde{b}_{t-1}$ and $\tilde{\tau}_{t}$. So $\hat{\gamma}_{O L S}$ mixes the correlation information from both channels, which obscures the true fiscal policy behavior.

\section{GMM: Basic Setup}

To overcome the pitfall of OLS regression on the fiscal policy rule, we apply the Generalized Method of Moments (GMM) ${ }^{13}$ for estimation and inference.

As assumed earlier, innovation to the fiscal policy shock, $\varepsilon_{\psi_{t}}$, is an i.i.d. random variable with zero mean, which implies the following moment condition

$$
E\left[\varepsilon_{\psi_{t}} \mid \mathcal{I}_{t-1}\right]=0
$$

where $E\left[\cdot \mid \mathcal{I}_{t-1}\right]$ is the conditional expectation operator with information up to period $t-1$. Rearranging (12) using the lag operator, we get

$$
\left(1-\rho_{\psi} L\right) \tilde{\psi}_{t}=\psi_{0}+\varepsilon_{\psi_{t}}
$$

Pre-multiplying (19) on both sides by $\left(1-\rho_{\psi} L\right)$, we get

$$
\left(1-\rho_{\psi} L\right) \tilde{\tau}_{t}=\left(1-\rho_{\psi} L\right) \gamma_{0}+\gamma\left(1-\rho_{\psi} L\right) \tilde{b}_{t-1}+\psi_{0}+\varepsilon_{\psi_{t}}
$$

\footnotetext{
${ }^{13}$ Hamilton (1994) provides a nice description of the basic GMM procedure. Canova (2007) and Ruge-Murcia (2007), among others, have more specific discussion of GMM in the context of estimating DSGE models.
} 
where (31) has been applied. With (32), condition (30) can be written as

$$
E\left[\delta-\tilde{\tau}_{t}+\rho_{\psi} \tilde{\tau}_{t-1}+\gamma \tilde{b}_{t-1}-\gamma \rho_{\psi} \tilde{b}_{t-2} \mid \mathcal{I}_{t-1}\right]=0
$$

where $\delta \equiv\left(1-\rho_{\psi}\right) \gamma_{0}+\psi_{0}$. Moment condition (33) basically says $\varepsilon_{\psi_{t}}$ is orthogonal to the information set $\mathcal{I}_{t-1}$. By choosing a set of instrumental variables from $\mathcal{I}_{t-1}$, say $z_{t}$, we are able to set up a series of moment conditions, based on which GMM estimation can be applied. More specifically, the set of population moment conditions looks like

$$
E\left[\left(\delta-\tilde{\tau}_{t}+\rho_{\psi} \tilde{\tau}_{t-1}+\gamma \tilde{b}_{t-1}-\gamma \rho_{\psi} \tilde{b}_{t-2}\right) \otimes z_{t}\right]=0
$$

where $z_{t}$ is the $(r \times 1)$ vector of instrumental variables and $\otimes$ denotes kronecker product. Totally we have three parameters to estimate, i.e. $\Theta \equiv\left[\gamma, \rho_{\psi}, \delta\right]$. Since the moment conditions (34) are nonlinear in the parameters, the GMM specification needs to be over-identified $(r>3)$ to pin down $\gamma$, which is the parameter to our central interest.

To implement GMM estimation, we derive the following sample moments which are analogous to $(34)$

$$
\mathrm{m}(\Theta)=\frac{1}{T} \sum_{t=3}^{T}\left(\delta-\tilde{\tau}_{t}+\rho_{\psi} \tilde{\tau}_{t-1}+\gamma \tilde{b}_{t-1}-\gamma \rho_{\psi} \tilde{b}_{t-2}\right) \otimes z_{t}
$$

Then we solve for the following minimization problem

$$
\min _{\Theta} \mathrm{m}(\Theta)^{\prime} \mathrm{W}(\Theta) \mathrm{m}(\Theta)
$$

where $\mathrm{W}(\Theta)$ is the weighting matrix. The solution of $(36)$ is the GMM estimator of $\Theta$, i.e. $\hat{\Theta}_{G M M}$. The asymptotic properties of $\hat{\Theta}_{G M M}$ have been well developed, based on which statistical inference on the fiscal policy behavior can be drawn.

\section{Monte Carlo Experiments}

In this section, we calibrate the model to the U.S. data and carry out a series of Monte Carlo experiments to illustrate the distinct small-sample performance of OLS and GMM in identifying fiscal policy behavior. 
In the experiment, we arbitrarily choose $z_{t}=\left[1, \tilde{b}_{t-1}, \tilde{\tau}_{t-1}, \tilde{b}_{t-2}, \tilde{\tau}_{t-2}\right]^{\prime}$ and carry out two-step GMM. The weighting matrix in the first step is identity matrix and the construction of the optimal weighting matrix in the second step follows Newey and West (1987). The implementation is based on the GMM and optimization program libraries in MATLAB written by Cliff $^{14}$.

\subsection{Simultaneity Bias: A Digression}

First, in the region of $[\alpha, \gamma]$ space that is corresponding to the non-Ricardian equilibrium, we set up a grid where both parameters range from 0.01 to 0.99 with increments of 0.01. Symmetrically, in the region that is corresponding to the Ricardian equilibrium, we set up a grid ranging from 1.01 to 1.99 with increments of 0.01. For both regions, we calibrate $\left[y, \beta, \delta, \gamma_{0}, \sigma_{\theta}, \sigma_{\psi}\right]$ in the same way as case III of section 3 . We choose moderate values for $\rho_{\theta}$ and $\rho_{\psi}$, which are 0.75 and 0.9 , respectively.

As a digression from the Monte Carlo experiments, we calculate the simultaneity bias for both regions according to the formula derived in Appendix $\mathrm{C}$, which provides more insights into the Monte Carlo experiment results. The simultaneity bias is displayed in Figure 3 and 4. In Figure 3, which is for non-Ricardian region, it is noticeable that the bias is positive when $\alpha$ is smaller than 0.3 and turns to negative as $\alpha$ gets larger. Besides, the negative bias is nonlinear in $\alpha$, which is indicated by the U-shaped plane. This is because when $\alpha$ is very small, the expected surplus effect dominates the expected seigniorage effect, which implies positive correlation between $\tilde{b}_{t-1}$ and $\tilde{\psi}_{t}$ and thus positive bias. In these cases, monetary policy is very passive and the nominal interest rate is nearly pegged. So the volatility of expected inflation and seigniorage is relatively small compared to the cases when $\alpha$ is large. From (21), we know that the volatility of $\tilde{b}_{t-1}$ should be relatively small, which makes the simultaneity bias relatively large in magnitude. As $\alpha$ gets larger, the expected seigniorage effect starts to dominate, which turns the correlation between $\tilde{b}_{t-1}$ and $\tilde{\psi}_{t}$ to negative. However, the expected seigniorage effect is not linear in $\alpha$. In fact, there is an underlying Laffer curve explaining the nonlinearity. As the economy gets to the downward-sloping

\footnotetext{
${ }^{14}$ The MATLAB code is located at http://mcliff.cob.vt.edu/ with documentation Cliff (2003).
} 
side of the Laffer curve, higher $\alpha$ induces weaker seigniorage effect, which makes the expected surplus effect relatively stronger and drives the bias up back to zero after a certain point. In figure 4 , which is for Ricardian region, the bias is always negative and turns out to be a downward-sloping plane in $\gamma$. This is because as $\gamma$ gets larger, taxes respond to government debt more strongly. This makes the expected seigniorage

less volatile because the wealth effect is weaker. Through $(21), \operatorname{var}\left(\tilde{b}_{t-1}\right)$ gets smaller, which makes the bias larger in magnitude.

\section{$5.2 \quad$ Experiment 1}

The first experiment is to explore the accuracy of the estimator of $\gamma$ from both OLS and GMM estimation. Specifically, for each combination of $\alpha$ and $\gamma$ in each region, we simulate 1000 independent data sets according to (17) and (18), each with 300 quarters. Based on each data set, the econometrician runs OLS regression on (19) and then implements GMM procedure (36). With each estimator, the econometrician tests the following hypotheses

$$
H_{0}: \gamma=\gamma_{0} \quad H_{1}: \gamma \neq \gamma_{0}
$$

where $\gamma_{0}$ is the true value of $\gamma$ at that grid point. The nominal size of the test is $5 \%$. Since the econometrician is always under the null hypothesis, we finally calculate the empirical size at each grid point based on the 1000 repetitions.

Because of the computational cost, we define a more sparse grid for each region. Specifically, in the non-Ricardian case, both parameters range from 0.1 to 0.9 with increments of 0.1 ; in the Ricardian case, both parameters range from 1.1 to 1.9 with increments of 0.1 . The results are organized in Table 6 and 6 , where Table 6 displays the empirical size of both methods in the non-Ricardian region and Table 6 is for the Ricardian region. In each table, rows are for $\gamma$ and columns are for $\alpha$. The empirical size before "/" in each entry is based on OLS regression and that after "/" is based on GMM.

In Table 6, it is obvious that OLS regression has severe size distortion over the whole region, especially when either $\alpha$ or $\gamma$ increases. Generally speaking, the size 
distortion of the OLS approach is due to the fact that the OLS estimator is inconsistent, which results in the poor accuracy of $\hat{\gamma}_{O L S}$. In contrast, $\hat{\gamma}_{G M M}$ is consistent and the empirical size of GMM is around the nominal size over the whole region.

Table 6 shows the same pattern as in Table 6 . One thing to note is that in Table 6, GMM has relatively high empirical size when $\gamma$ gets closer to the boundary value. With other experiments, we find that, when $\gamma$ is relatively small, the empirical size of GMM approaches to the nominal size as $T$ increases. This happens maybe because in small samples: (1) information is not enough to pin down the parameter accurately; (2) the asymptotic standard error of $\hat{\gamma}_{G M M}$ understates the true volatility of $\hat{\gamma}_{G M M}$, which induces poor statistical inference. Even so, we still get strong evidence that GMM performs uniformly better than OLS regression in terms of accuracy of the estimator.

\subsection{Experiment 2}

The second experiment is a scenario where the econometrician tries to identify fiscal policy behavior with both OLS and GMM methods. The basic setup is the same as in experiment 1 except that now the econometrician tests the following hypotheses

$$
H_{0}: \gamma \geq 1 \quad H_{1}: \gamma<1
$$

where the null and the alternative hypotheses are corresponding to passive and active fiscal policy, respectively. In the non-Ricardian region, the econometrician is under the alternative and we calculate the empirical power. While in the Ricardian region, the econometrician is under the null and we calculate the empirical size.

We use the same grid as in experiment 1. The results are organized in Table 6 and 6, where Table 6 displays the empirical power of both methods in the non-Ricardian region and Table 6 displays the empirical size of both methods in the Ricardian region. The empirical power/size before "/" in each entry is based on OLS regression and that after "/" is based on GMM.

In Table 6, it is clear that OLS regression has low power as $\alpha$ gets small, e.g. $\alpha<0.3$, which is because in these cases, $\hat{\gamma}_{O L S}$ is biased up significantly. When $\alpha$ is relatively small, the power of OLS regression gets even lower as $\gamma$ gets larger. For 
instance, OLS regression has zero power when $\alpha<0.2$ and $\gamma>0.7$. On the other hand, OLS regression has power equal to 1 as $\alpha$ gets large, e.g. $\alpha>0.5$. This comes from the fact that $\hat{\gamma}_{O L S}$ is downward biased when $\alpha$ is at relatively high levels. This pattern indicates that how monetary policy behaves has impact on the reliability of the OLS-based identification results, which is an important implication on the empirical work that applies OLS regression on the identification of fiscal policy behavior. If monetary policy is very passive, such as interest rate pegging $(\alpha \approx 0)$, OLS regression has a very hard time to recover an active fiscal policy. So a world consistent with the fiscal theory of price level is difficult to be identified in practice. Considering the literature trying to identify fiscal policy behavior or testing fiscal sustainability using OLS regression, such as Bohn (1998), most papers get results favoring passive fiscal policy. By connecting with our analysis, it might be the case that the fiscal policy in place is actually active, which is just not identifiable by OLS approach. For GMM, there is an overall power improvement compared to OLS regression. Since $\hat{\gamma}_{G M M}$ is consistent, there is no abnormal pattern in its power performance. Generally speaking, GMM has uniformly high power when $\gamma$ is small, which is useful to identify a world of the fiscal theory of price level. The power of GMM decreases as $\gamma$ gets closer to the boundary value, which is a small-sample problem. According to some complementary experiments, this could be remedied to some extent with larger sample size.

In Table 6, the size performance of OLS and GMM is in sharp contrast. Since $\hat{\gamma}_{O L S}$ is inconsistent, OLS regression has size distortion, especially when $\gamma$ is relatively small. In these cases, $\hat{\gamma}_{O L S}$ is biased downwards. Because the asymptotic standard error is also biased downwards in small samples, passive fiscal policy near the boundary is hard to be identified by OLS regression. For GMM, the empirical size is zero for most cases except for the experiments near the boundary, where the empirical size is slightly greater than zero but smaller than the nominal size.

Overall, GMM outperforms the OLS regression over the whole parameter space in terms of size and power. Therefore, we expect more reliable identification results from GMM. 


\section{Conclusion}

If fiscal policy is specified as a single-equation rule, in which primary surplus is defined as a function of lagged government debt and other controlled variables, how can we identify fiscal authority's behavior in a reliable way? We focus our interest on the coefficient of lagged government debt and try to find the answer by starting from OLS regression on the fiscal policy rule, one of the common approaches applied in the current literature. From the rational expectations general equilibrium perspective, we illustrates that lagged government debt is generally endogenous and the OLS approach is invalid because of the simultaneity bias. Consequently, the OLS-based identification of fiscal policy behavior is unreliable. To correct for the simultaneity bias associated with the OLS approach, we find a series of moment conditions from the model and propose GMM estimation, which provides consistent estimator and reliable inference. Monte Carlo experiments compare OLS with GMM in terms of accuracy of the estimator, size and power, which turn out to support our proposal. As a general suggestion, people should be cautious of the existing OLS-based identification results of fiscal policy behavior and the empirical researchers should not consider OLS regression as a reliable tool when trying to identify fiscal policy behavior in the future.

The main purpose of this paper is to illustrate the existing methodological problem in a clear way and try to connect the econometric failure with macroeconomic theory more closely, which is best done in a specific model environment. Even though the results are based on the model setup and calibrated parameter values, the simultaneity bias problem examined here is general and robust to model specification and parameter values. As long as a fiscal policy rule, a basic component of the underlying general equilibrium structure, is specified and estimated by OLS regression, the results tend to be misleading.

In the future work, there are several issues we need to address. First, we want to see if the GMM-based identification is robust to the potential misspecification in the functional form of the fiscal policy rule. Second, we also want to see if the GMM-based identification is robust to the potential misspecification in the policy shock process. Third, we need to formally study the choice of instrumental variables, while in this 
paper we choose them in an arbitrary manner. As is well known, this matters for the parameter identification. Fourth, we would like to see if the bootstrap method is able to correct for the small-sample bias in the GMM standard error and provide better inference. 


\section{Appendix A: Solution of the Model}

To solve the model, we first log-linearize (7) and (9) as

$$
\begin{aligned}
& \hat{R}_{t}=E_{t} \hat{\pi}_{t+1} \\
& \hat{R}_{t}=\alpha \hat{\pi}_{t}+\hat{\theta}_{t}
\end{aligned}
$$

To get (39), we have imposed steady state condition $R=\beta^{-1}$. For simplicity, we assume $\pi=1$. Combining (39) and (40), we get

$$
E_{t} \hat{\pi}_{t+1}=\alpha \hat{\pi}_{t}+\hat{\theta}_{t}
$$

We then define the one-period-ahead endogenous forecasting error $\eta_{t+1} \equiv \hat{\pi}_{t+1}-E_{t} \hat{\pi}_{t+1}$ and express (41) as

$$
\hat{\pi}_{t+1}=\alpha \hat{\pi}_{t}+\hat{\theta}_{t}+\eta_{t+1}
$$

Next, we log-linearize (5), (8) and (10) as

$$
\begin{aligned}
m \hat{m}_{t}+b \hat{b}_{t}+\tau \hat{\tau}_{t} & =m \hat{m}_{t-1}-m \hat{\pi}_{t}+R b \hat{R}_{t-1}+R b \hat{b}_{t-1}-R b \hat{\pi}_{t} \\
m(R-1) \hat{m}_{t} & =R(\delta c-m) \hat{R}_{t} \\
\hat{\tau}_{t} & =\gamma \hat{b}_{t-1}+\hat{\psi}_{t}
\end{aligned}
$$

where relevant steady state conditions have been imposed. Combining (40), (43)-(45) and rearranging terms, we get

$$
\varphi_{1} \hat{\pi}_{t}+\hat{b}_{t}+\varphi_{2} \hat{\pi}_{t-1}-\left[\beta^{-1}-\gamma\left(\beta^{-1}-1\right)\right] \hat{b}_{t-1}+\varphi_{3} \hat{\theta}_{t}+\left(\beta^{-1}-1\right) \hat{\psi}_{t}+\varphi_{4} \hat{\theta}_{t-1}=0
$$

where

$$
\begin{aligned}
\varphi_{1} & \equiv \frac{m}{b}(\alpha \chi+1)+\beta^{-1} \\
\varphi_{2} & \equiv-\alpha\left[\frac{m}{b} \chi+\beta^{-1}\right] \\
\varphi_{3} & \equiv \frac{m}{b} \chi \\
\varphi_{4} & \equiv-\left[\frac{m}{b} \chi+\beta^{-1}\right]
\end{aligned}
$$


and $\chi \equiv 1 /(1-R)$ is the interest elasticity of money demand. It is straightforward to log-linearize (11) and (12) as

$$
\begin{aligned}
\hat{\theta}_{t} & =\rho_{\theta} \hat{\theta}_{t-1}+\varepsilon_{\theta_{t}} \\
\hat{\psi}_{t} & =\rho_{\psi} \hat{\psi}_{t-1}+\varepsilon_{\psi_{t}}
\end{aligned}
$$

After substituting (47) and (48) into (46), we get

$\varphi_{1} \hat{\pi}_{t+1}+\hat{b}_{t+1}=-\varphi_{2} \hat{\pi}_{t}+\left[\beta^{-1}-\gamma\left(\beta^{-1}-1\right)\right] \hat{b}_{t}-\left(\varphi_{3} \rho_{\theta}+\varphi_{4}\right) \hat{\theta}_{t}-\left(\beta^{-1}-1\right) \rho_{\psi} \hat{\psi}_{t}-\varphi_{3} \varepsilon_{\theta_{t+1}}-\left(\beta^{-1}-1\right) \varepsilon_{\psi_{t+1}}$

So far, (42), (47)-(49) form a self-contained system governing the dynamics of $\hat{\pi}_{t}$, $\hat{b}_{t}, \hat{\theta}_{t}$ and $\hat{\psi}_{t}$. We organize the linearized system in the following matrix form

$$
\Gamma_{0} Y_{t+1}=\Gamma_{1} Y_{t}+\Pi \eta_{t+1}+\Psi \varepsilon_{t+1}
$$

where $Y_{t+1}=\left[\hat{\pi}_{t+1}, \hat{b}_{t+1}, \hat{\theta}_{t+1}, \hat{\psi}_{t+1}\right]^{\prime}, \varepsilon_{t+1}=\left[\varepsilon_{\theta_{t+1}}, \varepsilon_{\psi_{t+1}}\right]^{\prime}$ and

$$
\begin{gathered}
\Gamma_{0}=\left[\begin{array}{llll}
1 & 0 & 0 & 0 \\
\varphi_{1} & 1 & 0 & 0 \\
0 & 0 & 1 & 0 \\
0 & 0 & 0 & 1
\end{array}\right], \quad \Pi=\left[\begin{array}{l}
1 \\
0 \\
0 \\
0
\end{array}\right], \quad \Psi=\left[\begin{array}{ccc}
0 & 0 \\
-\varphi_{3} & -\left(\beta^{-1}-1\right) \\
1 & 0 \\
0 & 1
\end{array}\right] \\
\Gamma_{1}=\left[\begin{array}{cccc}
\alpha & 0 & 1 & 0 \\
-\varphi_{2} & \beta^{-1}-\gamma\left(\beta^{-1}-1\right) & -\left(\varphi_{3} \rho_{\theta}+\varphi_{4}\right) & -\left(\beta^{-1}-1\right) \rho_{\psi} \\
0 & 0 & \rho_{\theta} & 0 \\
0 & 0 & 0 & \rho_{\psi}
\end{array}\right]
\end{gathered}
$$

Since $\Gamma_{0}$ is invertible, (50) can be expressed as

$$
Y_{t+1}=\Gamma_{1}^{*} Y_{t}+\Pi^{*} \eta_{t+1}+\Psi^{*} \varepsilon_{t+1}
$$

where $\Gamma_{1}^{*}=\Gamma_{0}^{-1} \Gamma_{1}, \Pi^{*}=\Gamma_{0}^{-1} \Pi$ and $\Psi^{*}=\Gamma_{0}^{-1} \Psi$. Applying a Jordan decomposition on $\Gamma_{1}^{*}$, the above equation becomes:

$$
\begin{aligned}
Y_{t+1} & =P \Lambda P^{-1} Y_{t}+\Pi^{*} \eta_{t+1}+\Psi^{*} \varepsilon_{t+1} \\
\Longrightarrow \quad P^{-1} Y_{t+1} & =\Lambda P^{-1} Y_{t}+P^{-1} \Pi^{*} \eta_{t+1}+P^{-1} \Psi^{*} \varepsilon_{t+1}
\end{aligned}
$$


where $\Lambda$ is a diagonal matrix with eigenvalues of $\Gamma_{1}^{*}$ on the main diagonal, which is in the following form

$$
\Lambda=\left[\begin{array}{cccc}
\alpha & 0 & 0 & 0 \\
0 & \beta^{-1}-\gamma\left(\beta^{-1}-1\right) & 0 & 0 \\
0 & 0 & \rho_{\theta} & 0 \\
0 & 0 & 0 & \rho_{\psi}
\end{array}\right]
$$

$P$ is a matrix, each column of which is the eigenvector of $\Gamma_{1}^{*}$ and is corresponding to the eigenvalue in $\Lambda$. Since there are no repeated eigenvalues, $P$ has full column rank and $P^{-1}$ can be shown as

$$
P^{-1}=\left[\begin{array}{cccc}
\frac{\alpha \varphi_{1}+\varphi_{2}}{\beta^{-1}-\gamma\left(\beta^{-1}-1\right)-\alpha} & 0 & \frac{\alpha \varphi_{1}+\varphi_{2}}{\left[\beta^{-1}-\gamma\left(\beta^{-1}-1\right)-\alpha\right]\left(\alpha-\rho_{\theta}\right)} & 0 \\
-\frac{\alpha \varphi_{1}+\varphi_{2}}{\beta^{-1}-\gamma\left(\beta^{-1}-1\right)-\alpha} & 1 & P_{2,3}^{-1} & -\frac{\left(\beta^{-1}-1\right) \rho_{\psi}}{\beta^{-1}-\gamma\left(\beta^{-1}-1\right)-\rho_{\psi}} \\
0 & 0 & 1 & 0 \\
0 & 0 & 0 & 1
\end{array}\right]
$$

where $P_{2,3}^{-1}=-\frac{\varphi_{1}\left[\beta^{-1}-\gamma\left(\beta^{-1}-1\right)\right]+\varphi_{2}}{\left[\beta^{-1}-\gamma\left(\beta^{-1}-1\right)-\alpha\right]\left[\beta^{-1}-\gamma\left(\beta^{-1}-1\right)-\rho_{\theta}\right]}-\frac{\varphi_{3} \rho_{\theta}+\varphi_{4}}{\beta^{-1}-\gamma\left(\beta^{-1}-1\right)-\rho_{\theta}}$. If the bounded equilibrium is determinate, the following conditions suppress the unstable root of the dynamic system and must hold for all $t$ :

$$
\begin{aligned}
& P^{i \cdot} Y_{t}=0 \\
& P^{i \cdot} \Pi^{*} \eta_{t+1}+P^{i \cdot} \Psi^{*} \varepsilon_{t+1}=0
\end{aligned}
$$

where $P^{i}$ is the $i$ th row of $P^{-1}$ and $i$ is the index denoting the unstable eigenvalue in $\Lambda$.

\section{Appendix B: Derivation of (20)}

For readers' convenience, let us rewrite (19) as below.

$$
\tilde{\tau}_{t}=\gamma_{0}+\gamma \tilde{b}_{t-1}+\tilde{\psi}_{t}
$$

Stacking all observations in vectors, we get

$$
\begin{aligned}
\tilde{\tau} & =\mathbf{1} \gamma_{0}+\gamma \tilde{b}_{-1}+\tilde{\psi} \\
& =\tilde{X} \Gamma+\tilde{\psi}
\end{aligned}
$$


where $\tilde{\tau}=\left[\tilde{\tau}_{2}, \ldots, \tilde{\tau}_{T}\right]^{\prime}, \tilde{b}_{-1}=\left[\tilde{b}_{1}, \ldots, \tilde{b}_{T-1}\right]^{\prime}, \tilde{\psi}=\left[\tilde{\psi}_{2}, \ldots, \tilde{\psi}_{T}\right]^{\prime}, \tilde{X}=\left[\mathbf{1}, \tilde{b}_{-1}\right], \Gamma=$ $\left[\gamma_{0}, \gamma\right]^{\prime}$ and $\mathbf{1}$ is a $((T-1) \times 1)$ vector consisting of 1 's. The OLS estimator of $\Gamma$ based on $(52)$ is

$$
\begin{aligned}
\hat{\Gamma}_{O L S} & =\left[\begin{array}{c}
\hat{\gamma}_{0 O L S} \\
\hat{\gamma}_{O L S}
\end{array}\right]=\left(\tilde{X}^{\prime} \tilde{X}\right)^{-1}\left(\tilde{X}^{\prime} \tilde{\tau}\right)=\Gamma+\left(\tilde{X}^{\prime} \tilde{X}\right)^{-1}\left(\tilde{X}^{\prime} \tilde{\psi}\right) \\
& =\left[\begin{array}{c}
\gamma_{0} \\
\gamma
\end{array}\right]+\left[\begin{array}{cc}
\mathbf{1}^{\prime} \mathbf{1} & \mathbf{1}^{\prime} \tilde{b}_{-1} \\
\tilde{b}_{-1}^{\prime} \mathbf{1} & \tilde{b}_{-1}^{\prime} \tilde{b}_{-1}
\end{array}\right]^{-1}\left[\begin{array}{c}
\mathbf{1}^{\prime} \tilde{\psi} \\
\tilde{b}_{-1}^{\prime} \tilde{\psi}
\end{array}\right] \\
& =\left[\begin{array}{c}
\gamma_{0} \\
\gamma
\end{array}\right]+\frac{1}{(T-1) \sum_{t=2}^{T} \tilde{b}_{t-1}^{2}-\left(\sum_{t=2}^{T} \tilde{b}_{t-1}\right)^{2}}\left[\begin{array}{c}
\sum_{t=2}^{T} \tilde{b}_{t-1}^{2} \sum_{t=2}^{T} \tilde{\psi}_{t}-\sum_{t=2}^{T} \tilde{b}_{t-1} \sum_{t=2}^{T}\left(\tilde{b}_{t-1} \tilde{\psi}_{t}\right) \\
(T-1) \sum_{t=2}^{T}\left(\tilde{b}_{t-1} \tilde{\psi}_{t}\right)-\sum_{t=2}^{T} \tilde{b}_{t-1} \sum_{t=2}^{T} \tilde{\psi}_{t}
\end{array}\right]
\end{aligned}
$$

Therefore, the probability limit of $\hat{\gamma}_{O L S}$ is

$$
\begin{aligned}
\operatorname{plim} \hat{\gamma}_{O L S} & =\gamma+\operatorname{plim} \frac{(T-1) \sum_{t=2}^{T}\left(\tilde{b}_{t-1} \tilde{\psi}_{t}\right)-\sum_{t=2}^{T} \tilde{b}_{t-1} \sum_{t=2}^{T} \tilde{\psi}_{t}}{(T-1) \sum_{t=2}^{T} \tilde{b}_{t-1}^{2}-\left(\sum_{t=2}^{T} \tilde{b}_{t-1}\right)^{2}} \\
& =\gamma+\frac{E\left(\tilde{b}_{t-1} \tilde{\psi}_{t}\right)-E\left(\tilde{b}_{t-1}\right) E\left(\tilde{\psi}_{t}\right)}{E\left(\tilde{b}_{t-1}^{2}\right)-\left(E\left(\tilde{b}_{t-1}\right)\right)^{2}}=\gamma+\frac{\operatorname{cov}\left(\tilde{b}_{t-1}, \tilde{\psi}_{t}\right)}{\operatorname{var}\left(\tilde{b}_{t-1}\right)}
\end{aligned}
$$

where $E(\cdot)$ is the expectation operator.

\section{Appendix C: Derivation of Simultaneity Bias}

- Case III (Non-Ricardian): $\gamma=\rho_{\theta}=0, \alpha \neq 0, \rho_{\psi} \neq 0$

Since $a_{21} \neq 0$ in (26), we substitute (26) into (46) and get

$$
\begin{aligned}
& \underbrace{\left(\frac{\varphi_{1}}{a_{21}}-1\right)}_{A_{1}} \hat{b}_{t}+\underbrace{\left[\frac{\varphi_{2}}{a_{21}}+\beta^{-1}-\gamma\left(\beta^{-1}-1\right)\right]}_{A_{2}} \hat{b}_{t-1}= \\
& \underbrace{\left(\varphi_{3}-\frac{\varphi_{1} a_{23}}{a_{21}}\right)}_{A_{3}} \hat{\theta}_{t}+\underbrace{\left(\beta^{-1}-1-\frac{\varphi_{1} a_{24}}{a_{21}}\right)}_{A_{4}} \hat{\psi}_{t}+\underbrace{\left(\varphi_{4}-\frac{\varphi_{2} a_{23}}{a_{21}}\right)}_{A_{5}} \hat{\theta}_{t-1}+\underbrace{\left(-\frac{\varphi_{2} a_{24}}{a_{21}}\right)}_{A_{6}} \hat{\psi}_{t-1}
\end{aligned}
$$


Since $A_{1} \neq 0$, we have

$$
\begin{aligned}
\tilde{b}_{t} & =\ln (b)+\frac{A_{3}+A_{5} L}{\left(A_{1}+A_{2} L\right)\left(1-\rho_{\theta} L\right)} \varepsilon_{\theta_{t}}+\frac{A_{4}+A_{6} L}{\left(A_{1}+A_{2} L\right)\left(1-\rho_{\psi} L\right)} \varepsilon_{\psi_{t}} \\
& =\ln (b)+\frac{\frac{A_{3}}{A_{1}}+\frac{A_{5}}{A_{1}} L}{\left(1+\frac{A_{2}}{A_{1}} L\right)\left(1-\rho_{\theta} L\right)} \varepsilon_{\theta_{t}}+\frac{\frac{A_{4}}{A_{1}}+\frac{A_{6}}{A_{1}} L}{\left(1+\frac{A_{2}}{A_{1}} L\right)\left(1-\rho_{\psi} L\right)} \varepsilon_{\psi_{t}} \\
& =\ln (b)+\underbrace{\frac{C_{3}+C_{5} L}{\left(1+C_{2} L\right)\left(1-\rho_{\theta} L\right)}}_{B_{1}} \varepsilon_{\theta_{t}}+\underbrace{\frac{C_{4}+C_{6} L}{\left(1+C_{2} L\right)\left(1-\rho_{\psi} L\right)}}_{B_{2}} \varepsilon_{\psi_{t}}
\end{aligned}
$$

where $C_{i}=A_{i} / A_{1}$, for $i=2,3,4,5,6$.

It can be shown that

$$
B_{1}=\frac{m_{1}}{1+C_{2} L}-\frac{n_{1}}{1-\rho_{\theta} L} \quad \text { and } \quad B_{2}=\frac{m_{2}}{1+C_{2} L}-\frac{n_{2}}{1-\rho_{\psi} L}
$$

where

$$
m_{1}=\frac{C_{2} C_{3}-C_{5}}{\rho_{\theta}+C_{2}}, \quad m_{2}=\frac{C_{2} C_{4}-C_{6}}{\rho_{\psi}+C_{2}}, \quad n_{1}=-\frac{C_{3} \rho_{\theta}+C_{5}}{\rho_{\theta}+C_{2}}, \quad n_{2}=-\frac{C_{4} \rho_{\psi}+C_{6}}{\rho_{\psi}+C_{2}}
$$

So we have

$$
\begin{aligned}
\tilde{b}_{t-1}= & \ln (b)+B_{1} \varepsilon_{\theta_{t-1}}+B_{2} \varepsilon_{\psi_{t-1}} \\
= & \ln (b)+\left(m_{1}-n_{1}\right) \varepsilon_{\theta_{t-1}}-\left(m_{1} C_{2}+n_{1} \rho_{\theta}\right) \varepsilon_{\theta_{t-2}}+\left(m_{1} C_{2}^{2}-n_{1} \rho_{\theta}^{2}\right) \varepsilon_{\theta_{t-3}}-\cdots \\
& +\left(m_{2}-n_{2}\right) \varepsilon_{\psi_{t-1}}-\left(m_{2} C_{2}+n_{2} \rho_{\psi}\right) \varepsilon_{\psi_{t-2}}+\left(m_{2} C_{2}^{2}-n_{2} \rho_{\psi}^{2}\right) \varepsilon_{\psi_{t-3}}-\cdots
\end{aligned}
$$

Since

$$
\tilde{\psi}_{t}=\frac{\varepsilon_{\psi_{t}}}{1-\rho_{\psi} L}=\varepsilon_{\psi_{t}}+\rho_{\psi} \varepsilon_{\psi_{t-1}}+\rho_{\psi}^{2} \varepsilon_{\psi_{t-2}}+\cdots
$$

We can show that

$$
\begin{aligned}
\operatorname{cov}\left(\tilde{b}_{t-1}, \tilde{\psi}_{t}\right) & =\left(m_{2}-n_{2}\right) \rho_{\psi} \sigma_{\psi}^{2}-\left(m_{2} C_{2}+n_{2} \rho_{\psi}\right) \rho_{\psi}^{2} \sigma_{\psi}^{2}+\left(m_{2} C_{2}^{2}-n_{2} \rho_{\psi}^{2}\right) \rho_{\psi}^{3} \sigma_{\psi}^{2}-\cdots \\
& =\left[\left(m_{2} \rho_{\psi}-m_{2} C_{2} \rho_{\psi}^{2}+m_{2} C_{2}^{2} \rho_{\psi}^{3}-\cdots\right)-\left(n_{2} \rho_{\psi}+n_{2} \rho_{\psi}^{3}+n_{2} \rho_{\psi}^{5}+\cdots\right)\right] \sigma_{\psi}^{2} \\
& =\left(\frac{m_{2} \rho_{\psi}}{1+C_{2} \rho_{\psi}}-\frac{n_{2} \rho_{\psi}}{1-\rho_{\psi}^{2}}\right) \sigma_{\psi}^{2}
\end{aligned}
$$


where the last equality holds because in non-Ricardian equilibrium, $C_{2}=-\alpha \beta>$ -1 and $\left|C_{2} \rho_{\psi}\right|<1$.

Finally, we can show that

$$
\begin{aligned}
\operatorname{var}\left(\tilde{b}_{t-1}\right)= & \operatorname{cov}\left(\tilde{b}_{t-1}, \tilde{b}_{t-1}\right) \\
= & {\left[\left(m_{1}-n_{1}\right)^{2}+\left(m_{1} C_{2}+n_{1} \rho_{\theta}\right)^{2}+\left(m_{1} C_{2}^{2}-n_{1} \rho_{\theta}^{2}\right)^{2}+\cdots\right] \sigma_{\theta}^{2} } \\
& +\left[\left(m_{2}-n_{2}\right)^{2}+\left(m_{2} C_{2}+n_{2} \rho_{\psi}\right)^{2}+\left(m_{2} C_{2}^{2}-n_{2} \rho_{\psi}^{2}\right)^{2}+\cdots\right] \sigma_{\psi}^{2} \\
= & \frac{m_{1}^{2} \sigma_{\theta}^{2}+m_{2}^{2} \sigma_{\psi}^{2}}{1-C_{2}^{2}}+\frac{n_{1}^{2} \sigma_{\theta}^{2}}{1-\rho_{\theta}^{2}}+\frac{n_{2}^{2} \sigma_{\psi}^{2}}{1-\rho_{\psi}^{2}}-\frac{2 m_{1} n_{1} \sigma_{\theta}^{2}}{1+C_{2} \rho_{\theta}}-\frac{2 m_{2} n_{2} \sigma_{\psi}^{2}}{1+C_{2} \rho_{\psi}}
\end{aligned}
$$

- Case IV (Ricardian):

Recall (27) and (28),

$$
\begin{aligned}
\tilde{\pi}_{t} & =-\frac{1}{\alpha-\rho_{\theta}} \tilde{\theta}_{t} \\
\eta_{t} & =-\frac{1}{\alpha-\rho_{\theta}} \varepsilon_{\theta_{t}}
\end{aligned}
$$

Let us define $g \equiv-1 /\left(\alpha-\rho_{\theta}\right)$ and $\lambda=\beta^{-1}-\gamma\left(\beta^{-1}-1\right)$. Since the equilibrium is Ricardian, the second row of system (51) is a stable first-order difference equation, from which we can solve for $\tilde{b}_{t}$ as a function of $\varepsilon_{\theta}$ and $\varepsilon_{\psi}$ :

$$
\begin{aligned}
\tilde{b}_{t}= & \ln (b)+\frac{D_{3}+D_{5} L}{\left(D_{1}+D_{2} L\right)\left(1-\rho_{\theta} L\right)} \varepsilon_{\theta_{t}}+\frac{D_{4}+D_{6} L}{\left(D_{1}+D_{2} L\right)\left(1-\rho_{\psi} L\right)} \varepsilon_{\psi_{t}} \\
& +\frac{D_{7}}{D_{1}+D_{2} L} \varepsilon_{\theta_{t}}+\frac{D_{8}}{D_{1}+D_{2} L} \varepsilon_{\psi_{t}}
\end{aligned}
$$


where

$$
\begin{aligned}
& D_{1}=1 \\
& D_{2}=-\lambda \\
& D_{3}=-\left(a_{21} g+a_{23}\right) \\
& D_{4}=-a_{24} \\
& D_{5}=\lambda\left(a_{21} g+a_{23}\right) \\
& D_{6}=\lambda a_{24} \\
& D_{7}=\left(-\frac{\varphi_{1} \alpha+\varphi_{2}}{\lambda-\alpha}-\varphi_{1}\right) g-\varphi_{3}+a_{23} \\
& D_{8}=-\left(\beta^{-1}-1\right)-\frac{\left(\beta^{-1}-1\right) \rho_{\psi}}{\lambda-\rho_{\psi}}
\end{aligned}
$$

It can be shown that

$$
\begin{aligned}
\frac{D_{3}+D_{5} L}{\left(D_{1}+D_{2} L\right)\left(1-\rho_{\theta} L\right)}= & \frac{m_{1}}{1-\lambda L}-\frac{n_{1}}{1-\rho_{\theta} L} \\
= & m_{1}+\lambda m_{1} L+\lambda^{2} m_{1} L^{2}+\cdots \\
& -n_{1}-\rho_{\theta} n_{1} L-\rho_{\theta}^{2} n_{1} L^{2}-\cdots \\
\frac{D_{4}+D_{6} L}{\left(D_{1}+D_{2} L\right)\left(1-\rho_{\psi} L\right)}= & \frac{m_{2}}{1-\lambda L}-\frac{n_{2}}{1-\rho_{\psi} L} \\
= & m_{2}+\lambda m_{2} L+\lambda^{2} m_{2} L^{2}+\cdots \\
& -n_{2}-\rho_{\psi} n_{2} L-\rho_{\psi}^{2} n_{2} L^{2}-\cdots
\end{aligned}
$$

where

$$
m_{1}=\frac{D_{5}+\lambda D_{3}}{\lambda-\rho_{\theta}}, \quad m_{2}=\frac{D_{6}+\lambda D_{4}}{\lambda-\rho_{\psi}}, \quad n_{1}=\frac{D_{5}+\rho_{\theta} D_{3}}{\lambda-\rho_{\theta}}, \quad n_{2}=\frac{D_{6}+\rho_{\psi} D_{4}}{\lambda-\rho_{\psi}}
$$

Besides,

$$
\begin{aligned}
& \frac{D_{7}}{D_{1}+D_{2} L}=D_{7}+\lambda D_{7} L+\lambda^{2} D_{7} L^{2}+\cdots \\
& \frac{D_{8}}{D_{1}+D_{2} L}=D_{8}+\lambda D_{8} L+\lambda^{2} D_{8} L^{2}+\cdots
\end{aligned}
$$


With some algebra, we can show

$$
\begin{aligned}
\operatorname{cov}\left(\tilde{b}_{t-1}, \tilde{\psi}_{t}\right)= & -\frac{\rho_{\psi} \sigma_{\psi}^{2}}{\left[1-\lambda \rho_{\psi}\right]\left(1-\rho_{\psi}^{2}\right)}<0 \\
\operatorname{var}\left(\tilde{b}_{t-1}\right)= & {\left[\frac{\left(m_{1}+D_{7}\right)^{2}}{1-\lambda^{2}}+\frac{n_{1}^{2}}{1-\rho_{\theta}^{2}}-\frac{2 n_{1}\left(m_{1}+D_{7}\right)}{1-\lambda \rho_{\theta}}\right] \sigma_{\theta}^{2} } \\
& +\left[\frac{\left(m_{2}+D_{8}\right)^{2}}{1-\lambda^{2}}+\frac{n_{2}^{2}}{1-\rho_{\psi}^{2}}-\frac{2 n_{2}\left(m_{2}+D_{8}\right)}{1-\lambda \rho_{\psi}}\right] \sigma_{\psi}^{2}
\end{aligned}
$$

Obviously, the simultaneity bias in the case of Ricardian equilibrium is always negative unless $\rho_{\psi}=0$. 


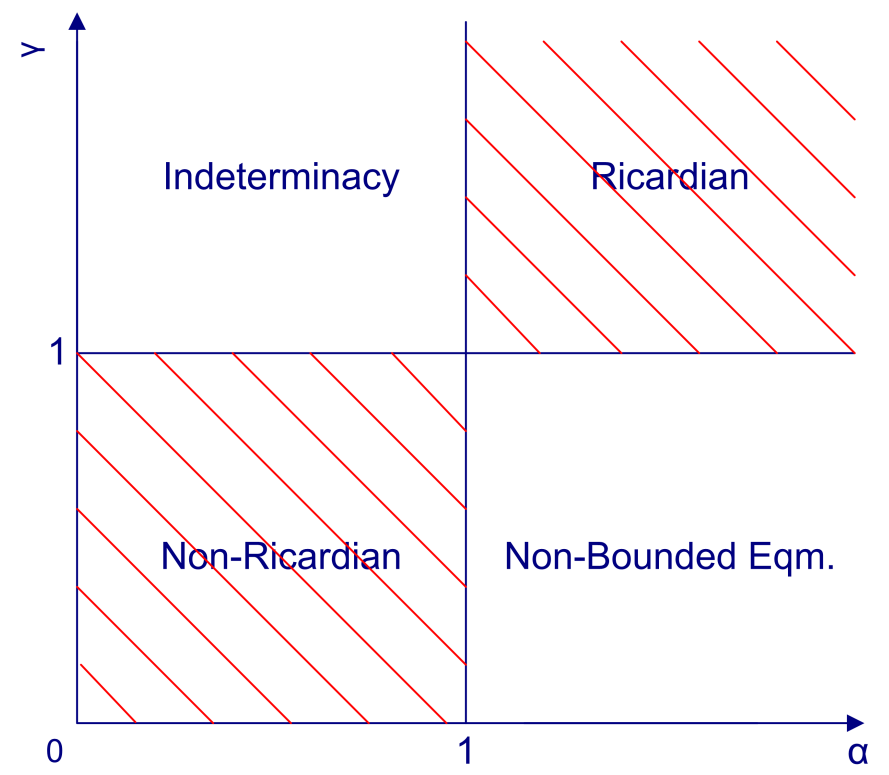

Figure 1: First Quadrant of $(\alpha, \gamma)$ Space

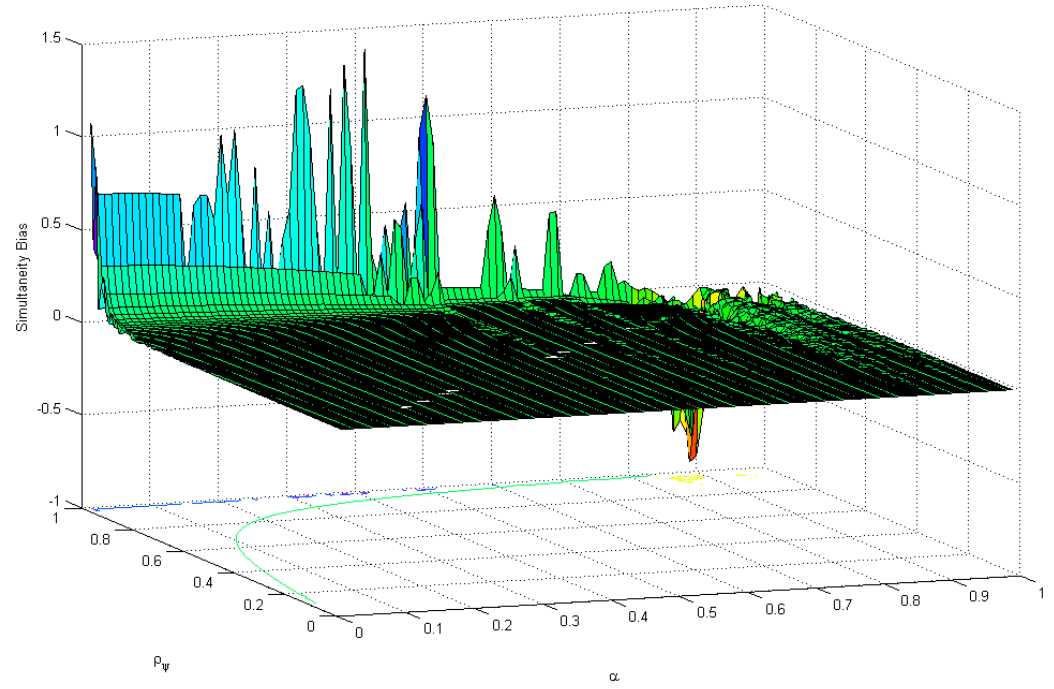

Figure 2: Simultaneity Bias in the Numerical Example (Case III) 


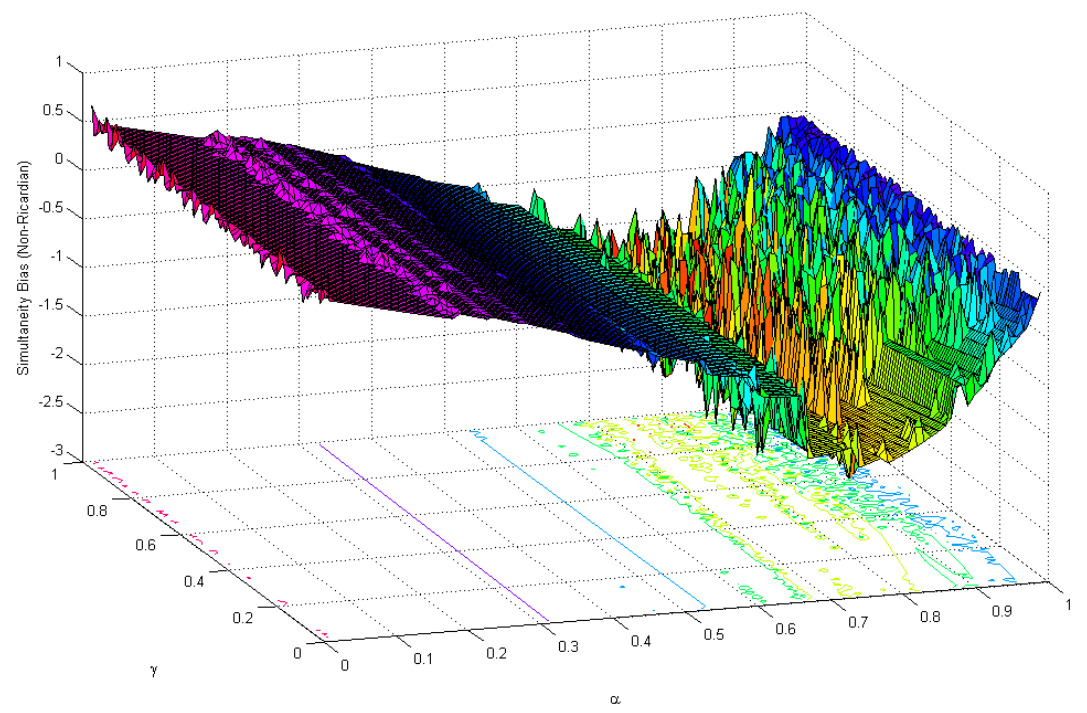

Figure 3: Simultaneity Bias (Non-Ricardian)

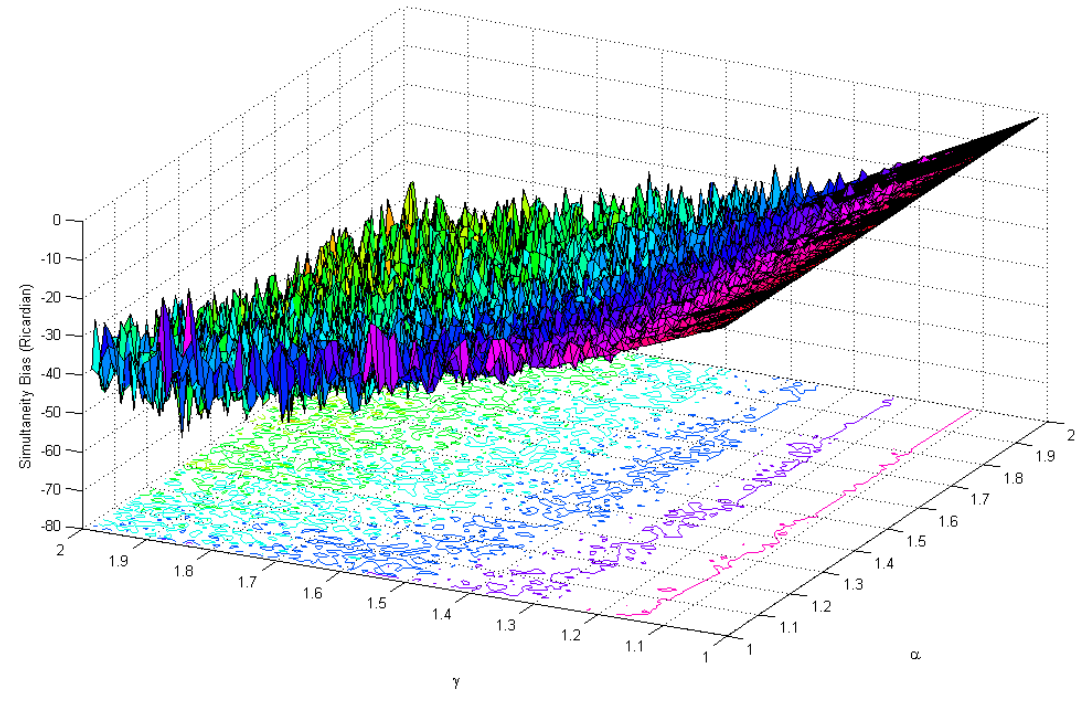

Figure 4: Simultaneity Bias (Ricardian) 


\begin{tabular}{|c|c|c|c|c|c|c|c|c|c|c|}
\hline ? & $\begin{array}{l}\infty \\
0 \\
0 \\
0 \\
8 \\
0 \\
0 \\
0\end{array}$ & $\begin{array}{l}\infty \\
0 \\
0 \\
0 \\
20 \\
0 \\
0 \\
0\end{array}$ & 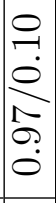 & 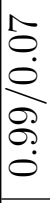 & $\begin{array}{l}\infty \\
0 \\
0 \\
0 \\
\delta \\
0 \\
0 \\
\end{array}$ & $\begin{array}{l}\infty \\
0 \\
0 \\
0 \\
8 \\
0 \\
-1 \\
\end{array}$ & 吕 & $\frac{0}{0}$ & $\frac{\mathscr{g}}{\varepsilon}$ & $\begin{array}{l}\stackrel{0}{0} \\
0 \\
0 \\
\tilde{\sigma}\end{array}$ \\
\hline$\stackrel{\infty}{0}^{\infty}$ & $\begin{array}{l}\infty \\
0 \\
0 \\
0 \\
8 \\
0 \\
0\end{array}$ & $\begin{array}{l}1 \\
0 \\
0 \\
\infty \\
0 \\
0 \\
0\end{array}$ & $\begin{array}{l}\infty \\
0 \\
0 \\
0 \\
\\
0 \\
0 \\
0\end{array}$ & $\begin{array}{l}\infty \\
0 \\
0 \\
0 \\
\delta \\
0 \\
0\end{array}$ & $\begin{array}{l}1 \\
0 \\
0 \\
0 \\
\delta \\
0 \\
0 \\
0\end{array}$ & $\begin{array}{l}\infty \\
0 \\
0 \\
0 \\
8 \\
- \\
-\end{array}$ & $\begin{array}{l}\hat{\sigma} \\
0 \\
0 \\
0 \\
8 \\
-\end{array}$ & $\underset{0}{\infty}$ & ह & $\begin{array}{l}\Xi \\
\Xi \\
0 \\
\check{0}\end{array}$ \\
\hline to. & $\begin{array}{l}\infty \\
0 \\
0 \\
0 \\
\text { } 1 \\
\infty \\
0 \\
0\end{array}$ & $\mid \begin{array}{c}\infty \\
0 \\
\dot{0} \\
\delta \\
\infty \\
0 \\
0\end{array}$ & 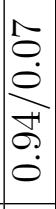 & $\begin{array}{l}0 \\
0 \\
0 \\
0 \\
0 \\
0 \\
0\end{array}$ & $\begin{array}{l}\infty \\
0 \\
0 \\
0 \\
0 \\
0 \\
0\end{array}$ & 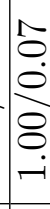 & $\mid$\begin{tabular}{l}
0 \\
$\stackrel{0}{0}$ \\
0 \\
8 \\
8 \\
\hdashline
\end{tabular} & $\stackrel{\infty}{0}$ & s & 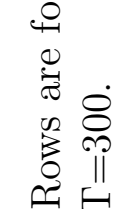 \\
\hline$\stackrel{\leftrightarrow}{0}$ & 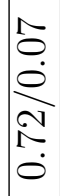 & $\begin{array}{l}1 \\
0 \\
0 \\
0 \\
\partial \\
\infty \\
\dot{0}\end{array}$ & $\begin{array}{l}\infty \\
0 \\
0 \\
0 \\
120 \\
\infty \\
0 \\
0\end{array}$ & $\begin{array}{l}N \\
0 \\
0 \\
\infty \\
\infty \\
\infty \\
0 \\
0\end{array}$ & $\begin{array}{l}1 \\
0 \\
0 \\
0 \\
8 \\
0 \\
0 \\
0\end{array}$ & $\begin{array}{l}0 \\
0 \\
0 \\
0 \\
0 \\
\varrho \\
0\end{array}$ & \begin{tabular}{l}
$\infty$ \\
$\stackrel{0}{0}$ \\
0 \\
0 \\
0 \\
\hdashline
\end{tabular} & $\frac{0}{2}$ & 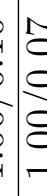 & 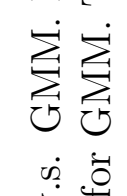 \\
\hline 10 & $\begin{array}{l}0 \\
0 \\
0 \\
0 \\
0 \\
20 \\
0 \\
0\end{array}$ & $\mid \begin{array}{c}\infty \\
0 \\
0 \\
0 \\
0 \\
2 \\
0 \\
0\end{array}$ & $\mid \begin{array}{c}\infty \\
0 \\
0 \\
\infty \\
0 \\
0 \\
0\end{array}$ & 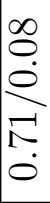 & $\begin{array}{l}0 \\
0 \\
0 \\
2 \\
12 \\
0 \\
0\end{array}$ & 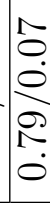 & $\mid \begin{array}{l}\infty \\
0 \\
0 \\
0 \\
0 \\
0 \\
0\end{array}$ & 告 & $\left\{\begin{array}{l}\frac{b}{a} \\
\varrho \\
a \\
c\end{array}\right.$ & 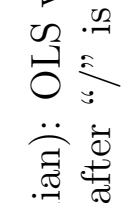 \\
\hline$\ddot{\circ}$ & $\begin{array}{l}8 \\
0 \\
0 \\
\infty \\
0 \\
+! \\
0\end{array}$ & $\mid \begin{array}{c}1 \\
0 \\
0 \\
0 \\
\infty \\
+1 \\
0 \\
0\end{array}$ & 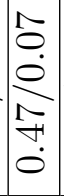 & $\begin{array}{l}1 \\
0 \\
0 \\
0 \\
0 \\
0 \\
0 \\
0\end{array}$ & $\begin{array}{l}1 \\
0 \\
0 \\
0 \\
0 \\
0 \\
0 \\
0 \\
0\end{array}$ & $\begin{array}{l}8 \\
0 \\
0 \\
0 \\
i ? \\
0 \\
0\end{array}$ & $\begin{array}{l}\mathscr{8} \\
0 \\
0 \\
N \\
\\
0\end{array}$ & $\frac{\infty}{0}$ & 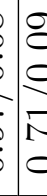 & 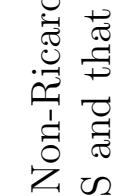 \\
\hline$\stackrel{?}{0}$ & 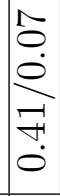 & 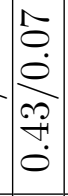 & 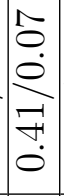 & $\begin{array}{l}\infty \\
0 \\
0 \\
\infty \\
\infty \\
\vdots \\
0 \\
0\end{array}$ & 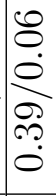 & \begin{tabular}{l}
$\infty$ \\
0 \\
$\dot{0}$ \\
\multirow{2}{*}{} \\
$\stackrel{0}{0}$
\end{tabular} & $\begin{array}{l}\mathscr{0} \\
\stackrel{0}{0} \\
\mathscr{D} \\
\stackrel{0}{0} \\
0\end{array}$ & $\begin{array}{l}\infty \\
0 \\
0 \\
\infty \\
0 \\
0\end{array}$ & $\left\{\begin{array}{l}a \\
a \\
a \\
a \\
c\end{array}\right.$ & 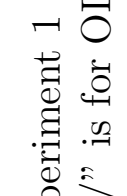 \\
\hline$\stackrel{\sim}{O}$ & $\mid \begin{array}{c}8 \\
0 \\
0 \\
0 \\
0 \\
\vdots \\
0\end{array}$ & $\mid \begin{array}{c}0 \\
0 \\
0 \\
0 \\
0 \\
+1 \\
0 \\
0\end{array}$ & 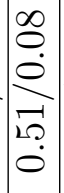 & $\frac{1}{0}$ & $\begin{array}{l}1 \\
0 \\
0 \\
0 \\
0 \\
0 \\
0\end{array}$ & $\begin{array}{l}\hat{1} \\
0 \\
0 \\
\infty \\
0 \\
10 \\
0\end{array}$ & $\begin{array}{l}\infty \\
0 \\
0 \\
0 \\
0 \\
\infty \\
0\end{array}$ & 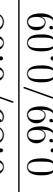 & : & 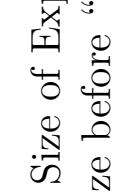 \\
\hline$\ddot{0}$ & $\begin{array}{l}1 \\
0 \\
0 \\
\infty \\
\infty \\
0 \\
0 \\
0\end{array}$ & $\left|\begin{array}{c}\hat{0} \\
0 \\
0 \\
\sigma \\
0 \\
0 \\
0\end{array}\right|$ & $\begin{array}{l}\mathscr{0} \\
\dot{0} \\
\dot{0} \\
\hat{R} \\
\dot{0}\end{array}$ & 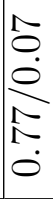 & $\begin{array}{l}1 \\
0 \\
0 \\
0 \\
0 \\
0 \\
0\end{array}$ & $\begin{array}{l}1 \\
0 \\
0 \\
0 \\
0 \\
0 \\
0\end{array}$ & $\mid \begin{array}{l}\infty \\
0 \\
0 \\
0 \\
0 \\
0 \\
-\end{array}$ & 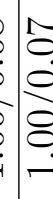 & 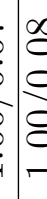 & 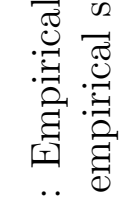 \\
\hline & 0 & $\stackrel{\sim}{0}$ & $\ddot{\leftrightarrow}$ & 8. & $\stackrel{1}{0}$ & ?. & 1 & $\infty$ & $\dot{p}$ & 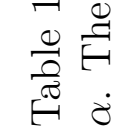 \\
\hline
\end{tabular}




\begin{tabular}{|c|c|c|c|c|c|c|c|c|c|c|}
\hline D & 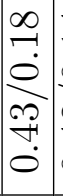 & 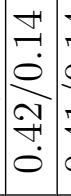 & 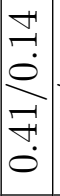 & 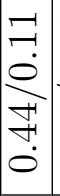 & $\begin{array}{c}0 \\
\stackrel{1}{0} \\
0 \\
0 \\
0 \\
0 \\
0\end{array}$ & $\begin{array}{l}\infty \\
0 \\
0 \\
0 \\
0 \\
10 \\
0\end{array}$ & 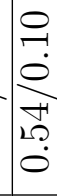 & $\begin{array}{l}1 \\
0 \\
0 \\
20 \\
20 \\
0\end{array}$ & 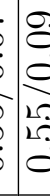 & $\begin{array}{l}\dot{0} \\
\dot{0} \\
\dot{0}\end{array}$ \\
\hline ه & 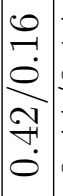 & $\left(\begin{array}{l}\overrightarrow{1} \\
\dot{0} \\
\dot{0} \\
\stackrel{+}{+} \\
\dot{0}\end{array}\right.$ & 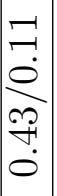 & 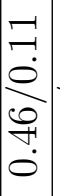 & $\begin{array}{l}\infty \\
0 \\
0 \\
0 \\
0 \\
0 \\
0 \\
0 \\
0\end{array}$ & 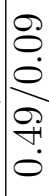 & \begin{tabular}{l}
0 \\
0 \\
0 \\
0 \\
\multirow{0}{0}{} \\
$i$ \\
0 \\
0
\end{tabular} & $\mid \begin{array}{l}0 \\
0 \\
0 \\
20 \\
10 \\
0 \\
0\end{array}$ & $\begin{array}{l}\infty \\
\varrho \\
0 \\
0 \\
0 \\
0 \\
0\end{array}$ & $\frac{\Xi}{\Xi}$ \\
\hline- & 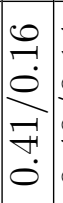 & $\begin{array}{c}+ \\
+ \\
\dot{0} \\
0 \\
\stackrel{0}{+} \\
\dot{0}\end{array}$ & 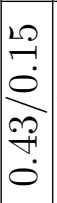 & $\begin{array}{c}0 \\
⿱ \\
\dot{0} \\
0 \\
0 \\
\stackrel{0}{0} \\
0\end{array}$ & $\begin{array}{l}8 \\
0 \\
0 \\
0 \\
0 \\
0 \\
0 \\
0\end{array}$ & 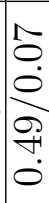 & $\begin{array}{l}0 \\
0 \\
0 \\
0 \\
10 \\
10 \\
0\end{array}$ & $\begin{array}{l}\infty \\
0 \\
0 \\
0 \\
10 \\
0 \\
0\end{array}$ & $\left\{\begin{array}{l}1 \\
c \\
c \\
c \\
c\end{array}\right.$ & 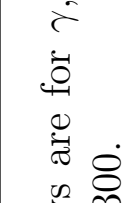 \\
\hline نُ & 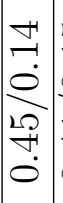 & 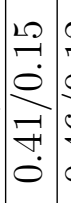 & 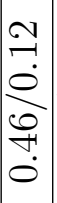 & 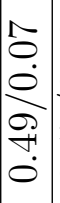 & 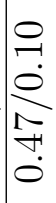 & \begin{tabular}{l}
$\infty$ \\
0 \\
0 \\
0 \\
$\infty$ \\
\multirow{2}{0}{} \\
0 \\
0
\end{tabular} & $\mid \begin{array}{c}0 \\
0 \\
0 \\
0 \\
20 \\
0 \\
0\end{array}$ & $\begin{array}{l}1 \\
0 \\
0 \\
\infty \\
\infty \\
1 \\
0 \\
0\end{array}$ & $\left\{\begin{array}{l}1 \\
c \\
0 \\
0 \\
0 \\
c\end{array}\right.$ & 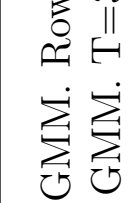 \\
\hline نْ & 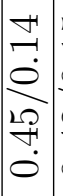 & 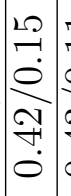 & 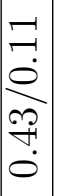 & $\begin{array}{c}\hat{1} \\
0 \\
0 \\
0 \\
0 \\
10 \\
0 \\
0\end{array}$ & $\mid \begin{array}{c}\mathscr{0} \\
\dot{0} \\
\dot{0} \\
\dot{10} \\
\dot{0}\end{array}$ & $\begin{array}{l}\infty \\
0 \\
0 \\
0 \\
i v \\
i ? \\
0\end{array}$ & 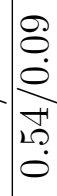 & $\begin{array}{c}\infty \\
0 \\
0 \\
0 \\
0 \\
0 \\
0\end{array}$ & $\left\{\begin{array}{l}1 \\
c \\
5 \\
5 \\
c \\
c\end{array}\right.$ & 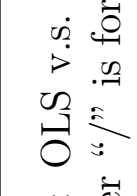 \\
\hline$\stackrel{\not}{\leftrightarrow}$ & 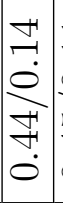 & 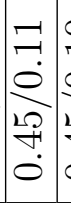 & $\mid \begin{array}{c}0 \\
\stackrel{2}{0} \\
\stackrel{10}{120} \\
+! \\
0 \\
0\end{array}$ & 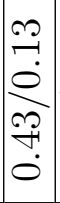 & 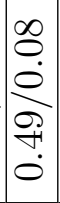 & $\mid \begin{array}{c}0 \\
0 \\
0 \\
0 \\
i ! n \\
0 \\
0\end{array}$ & $\begin{array}{l}8 \\
0 \\
0 \\
\dot{0} \\
\dot{2} \\
0\end{array}$ & \begin{tabular}{l}
$\infty$ \\
0 \\
0 \\
\multirow{2}{0}{} \\
$i$ \\
0 \\
0
\end{tabular} & $\left\{\begin{array}{l}a \\
a \\
i s \\
c\end{array}\right.$ & 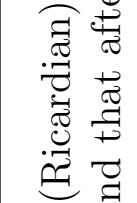 \\
\hline$\stackrel{\leftrightarrow}{\sim}$ & 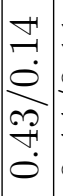 & 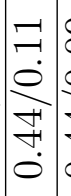 & $\begin{array}{l}2 \\
0 \\
0 \\
\\
\\
\dot{f} \\
0\end{array}$ & $\begin{array}{c}0 \\
0 \\
0 \\
0 \\
0 \\
+1 \\
\dot{0}\end{array}$ & $\begin{array}{c}\mathfrak{1} \\
0 \\
0 \\
\infty \\
\infty \\
+ \\
\dot{0}\end{array}$ & 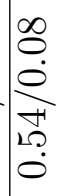 & $\begin{array}{l}0 \\
0 \\
0 \\
0 \\
\dot{0} \\
0 \\
0\end{array}$ & $\begin{array}{l}0 . \\
0 \\
0 \\
0 \\
0 \\
0 \\
0\end{array}$ & $\left\{\begin{array}{l}1 \\
c \\
25 \\
25 \\
c\end{array}\right.$ & 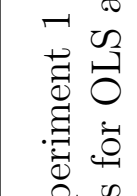 \\
\hline ฯ & 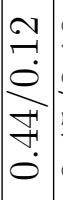 & $\begin{array}{c}0 \\
0 \\
0 \\
0 \\
10 \\
10 \\
+1 \\
0\end{array}$ & $\mid \begin{array}{c}0 \\
0 \\
0 \\
\infty \\
0 \\
+! \\
0\end{array}$ & 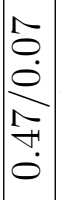 & $\begin{array}{c}\hat{D} \\
0 \\
0 \\
0 \\
0 \\
\dot{0} \\
0\end{array}$ & 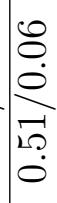 & $\begin{array}{l}0 \\
0 \\
0 \\
0 \\
0 \\
i ? \\
0 \\
0\end{array}$ & $\left\{\begin{array}{l}0 \\
0 \\
0 \\
20 \\
0 \\
0\end{array}\right.$ & a & 苟 \\
\hline$\neg$ & 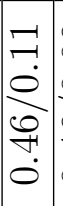 & 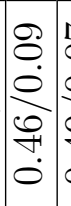 & 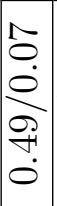 & 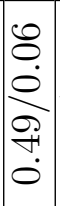 & 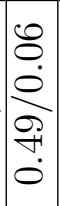 & $\mid \begin{array}{c}0 \\
0 \\
0 \\
0 \\
01 \\
0 \\
0\end{array}$ & $\begin{array}{l}0 \\
0 \\
0 \\
0 \\
0 \\
i ? \\
0 \\
0\end{array}$ & 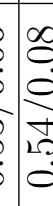 & a & 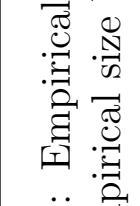 \\
\hline & ־ & $\stackrel{\sim}{-}$ & $\stackrel{?}{\sim}$ & $\stackrel{\leftrightarrow}{\oplus}$ & 年 & 0 & - & $\infty$ & & $\begin{array}{cc}\frac{0}{d} & 0 \\
\frac{\sigma}{\sigma} & \stackrel{d}{E}\end{array}$ \\
\hline
\end{tabular}




\begin{tabular}{|c|c|c|c|c|c|c|c|c|c|c|}
\hline$\theta$ & 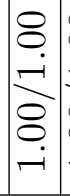 & $\begin{array}{c}8 \\
0 \\
\dot{-} \\
8 \\
8 \\
-1\end{array}$ & 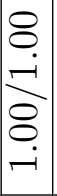 & 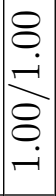 & 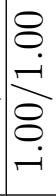 & $\begin{array}{l}8 \\
\\
\\
\\
8 \\
-1\end{array}$ & \begin{tabular}{l}
20 \\
$\infty$ \\
0 \\
0 \\
8 \\
\hdashline \\
-1
\end{tabular} & $\begin{array}{l}0 \\
2 \\
0 \\
0 \\
8 \\
8 \\
-1 \\
-1\end{array}$ & 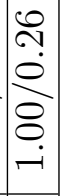 & 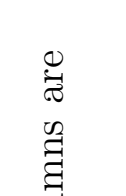 \\
\hline ڤ్ & 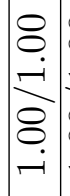 & \begin{tabular}{c}
8 \\
8 \\
\hdashline \\
8 \\
8 \\
$-i$
\end{tabular} & 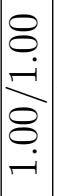 & 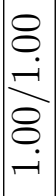 & 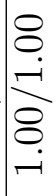 & 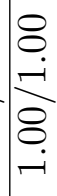 & $\begin{array}{l}1 \\
0 \\
0 \\
0 \\
8 \\
8 \\
-1\end{array}$ & 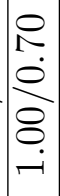 & 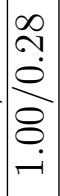 & $\begin{array}{l}0 \\
\dot{c} \\
\dot{0}\end{array}$ \\
\hline$\stackrel{1}{0}$ & 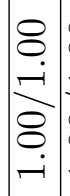 & 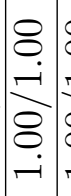 & 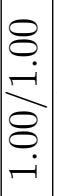 & 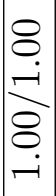 & 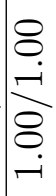 & & 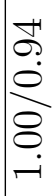 & \begin{tabular}{l}
$\infty$ \\
0 \\
0 \\
0 \\
8 \\
8 \\
\hdashline \\
$-i$
\end{tabular} & 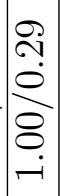 & 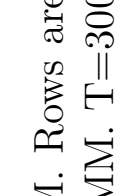 \\
\hline$\stackrel{0}{0}_{0}$ & 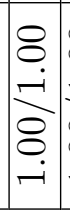 & 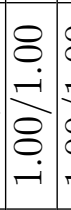 & 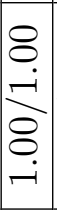 & 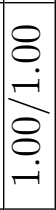 & 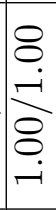 & 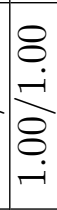 & $\begin{array}{l}2 \\
0 \\
0 \\
0 \\
8 \\
0 \\
-1\end{array}$ & $\begin{array}{l}0 \\
\dot{0} \\
0 \\
8 \\
0 \\
-1\end{array}$ & 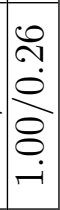 & 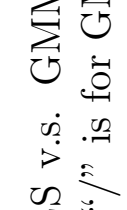 \\
\hline مُ & 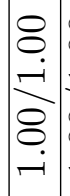 & 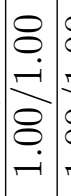 & 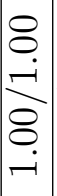 & 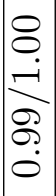 & $\mid \begin{array}{c}8 \\
\dot{\theta} \\
\dot{\delta} \\
\dot{\sigma} \\
\dot{0}\end{array}$ & $\frac{\partial}{2}$ & \begin{tabular}{l}
2 \\
$\infty$ \\
0 \\
0 \\
8 \\
8 \\
\hdashline \\
\hdashline
\end{tabular} & 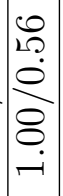 & 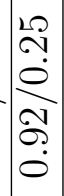 & 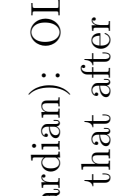 \\
\hline$\stackrel{+}{0}$ & 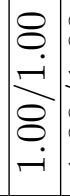 & 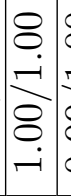 & 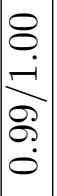 & 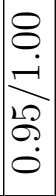 & $\begin{array}{c}8 \\
8 \\
\dot{i} \\
8 \\
8 \\
0 \\
\end{array}$ & $\begin{array}{l}20 \\
0 \\
0 \\
0 \\
\infty \\
\infty \\
0 \\
0\end{array}$ & $\begin{array}{l}0 \\
0 \\
\dot{0} \\
\dot{0} \\
0 \\
0\end{array}$ & 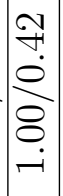 & $\mid \begin{array}{c}\vec{N} \\
\vdots \\
0 \\
0 \\
\infty \\
0 \\
0\end{array}$ & 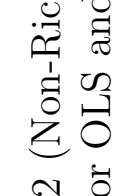 \\
\hline$\ddot{0}$ & 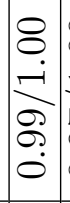 & 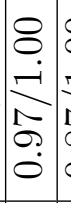 & $\begin{array}{c}8 \\
0 \\
\dot{+} \\
\\
\infty \\
\infty \\
0 \\
0\end{array}$ & 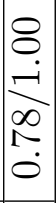 & $\begin{array}{l}\infty \\
0 \\
0 \\
0 \\
0 \\
0 \\
0\end{array}$ & $\begin{array}{l}\infty \\
\infty \\
0 \\
0 \\
10 \\
10 \\
0\end{array}$ & 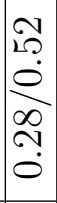 & 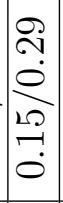 & 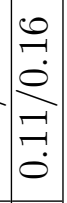 & 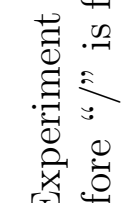 \\
\hline 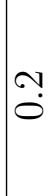 & 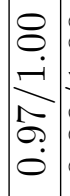 & \begin{tabular}{c}
8 \\
0 \\
\hdashline \\
0 \\
0 \\
0 \\
0 \\
0
\end{tabular} & $\mid \begin{array}{c}8 \\
0 \\
\dot{+} \\
\overrightarrow{0} \\
0 \\
0\end{array}$ & 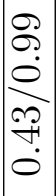 & 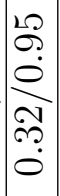 & 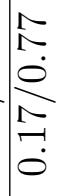 & $\mid \begin{array}{l}0 \\
0 \\
0 \\
0 \\
0 \\
0 \\
0\end{array}$ & 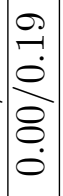 & $\mid \begin{array}{c}0 \\
\stackrel{ }{0} \\
0 \\
8 \\
0 \\
0 \\
0\end{array}$ & 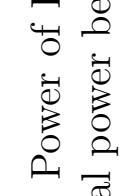 \\
\hline$\stackrel{1}{\circ}$ & 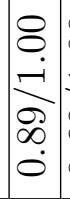 & \begin{tabular}{c}
8 \\
$\dot{8}$ \\
\hdashline \\
$\infty$ \\
0 \\
0 \\
0 \\
0
\end{tabular} & 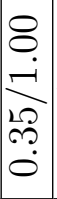 & 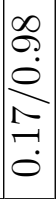 & $\begin{array}{c}8 \\
0 \\
0 \\
0 \\
\vdots \\
0 \\
0\end{array}$ & $\begin{array}{l}\vec{b} \\
\dot{0} \\
\dot{0} \\
\dot{0} \\
0\end{array}$ & $\begin{array}{l}1 \\
0 \\
0 \\
0 \\
8 \\
0 \\
0\end{array}$ & $\begin{array}{l}\infty \\
0 \\
\dot{0} \\
0 \\
8 \\
\dot{0} \\
\dot{0}\end{array}$ & $\begin{array}{l}2 \\
\dot{0} \\
\dot{0} \\
0 \\
\dot{0} \\
\dot{0}\end{array}$ & 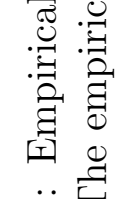 \\
\hline & $\ddot{0}$ & 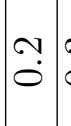 & $\ddot{3}$ & $\stackrel{+!}{0}$ & : & $\stackrel{0}{0}$ & & $\begin{array}{l}\infty \\
\dot{0}\end{array}$ & $\vec{p}$ & 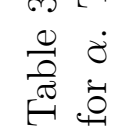 \\
\hline
\end{tabular}




\begin{tabular}{|c|c|c|c|c|c|c|c|c|c|c|}
\hline$D$ & 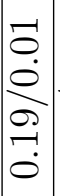 & $\left|\begin{array}{c}8 \\
0 \\
0 \\
\infty \\
-1 \\
\hdashline \\
0\end{array}\right|$ & $\mid \begin{array}{c}0 \\
0 \\
0 \\
0 \\
0 \\
\ddot{0} \\
0\end{array}$ & $\begin{array}{l}0 \\
0 \\
0 \\
\\
\\
\dot{0} \\
0\end{array}$ & $\begin{array}{l}8 \\
0 \\
0 \\
\dot{8} \\
\stackrel{+}{0} \\
0\end{array}$ & $\begin{array}{l}8 \\
0 \\
0 \\
0 \\
0 \\
\dot{0} \\
0\end{array}$ & $\begin{array}{l}\stackrel{0}{0} \\
\dot{0} \\
\ddot{\theta} \\
\dot{0}\end{array}$ & $\mid \begin{array}{l}8 \\
0 \\
0 \\
\Xi \\
0 \\
0\end{array}$ & 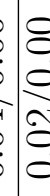 & $\begin{array}{l}\dot{\sigma} \\
\dot{0}\end{array}$ \\
\hline$\infty$. & $\mid \begin{array}{c}0 \\
0 \\
0 \\
0 \\
0 \\
\\
0\end{array}$ & $\left|\begin{array}{c}8 \\
0 \\
0 \\
0 \\
\overrightarrow{0} \\
0\end{array}\right|$ & $\mid \begin{array}{c}8 \\
0 \\
0 \\
0 \\
0 \\
0 \\
0\end{array}$ & $\begin{array}{c}8 \\
0 \\
0 \\
0 \\
0 \\
\qquad \dot{0} \\
0\end{array}$ & 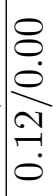 & $\begin{array}{l}8 \\
0 \\
0 \\
0 \\
0 \\
0 \\
0\end{array}$ & $\begin{array}{l}\stackrel{8}{0} \\
\dot{0} \\
\dot{\delta} \\
\dot{0}\end{array}$ & $\mid \begin{array}{l}8 \\
0 \\
0 \\
20 \\
0 \\
0\end{array}$ & 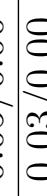 & 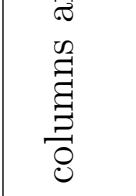 \\
\hline 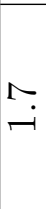 & 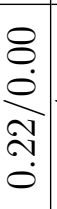 & $\begin{array}{c}8 \\
0 \\
0 \\
\\
\\
0\end{array} \mid$ & $\begin{array}{l}8 \\
\dot{0} \\
0 \\
0 \\
\ddot{0} \\
0\end{array}$ & 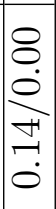 & $\begin{array}{l}8 \\
0 \\
0 \\
0 \\
\vdots \\
0\end{array}$ & $\begin{array}{l}8 \\
0 \\
0 \\
0 \\
0 \\
\dot{0} \\
0\end{array}$ & $\mid \begin{array}{l}8 \\
0 \\
\dot{0} \\
\dot{0} \\
\dot{0}\end{array}$ & $\mid \begin{array}{l}8 \\
0 \\
0 \\
\vdots \\
0 \\
0 \\
0\end{array}$ & 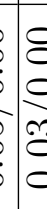 & $\begin{array}{l}\stackrel{0}{0} \\
0 \\
\stackrel{0}{\sigma} \\
\infty\end{array}$ \\
\hline ن & 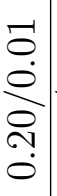 & $\mid$\begin{tabular}{c}
8 \\
0 \\
0 \\
$\infty$ \\
0 \\
\hdashline \\
0
\end{tabular} & $\begin{array}{c}8 \\
\stackrel{0}{0} \\
\stackrel{\infty}{\infty} \\
\stackrel{1}{-1} \\
0\end{array}$ & 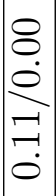 & 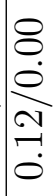 & $\begin{array}{l}8 \\
0 \\
0 \\
0 \\
0 \\
0\end{array}$ & $\begin{array}{l}\stackrel{8}{0} \\
\dot{0} \\
\stackrel{2}{8} \\
\dot{0}\end{array}$ & $\begin{array}{l}\varrho \\
\vdots \\
\vdots \\
\vdots \\
0 \\
0\end{array}$ & $\frac{\varrho}{a}$ & 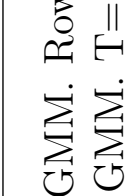 \\
\hline ن & 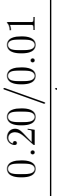 & 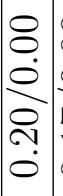 & \begin{tabular}{l}
8 \\
0 \\
0 \\
\\
\hdashline \\
0 \\
0
\end{tabular} & 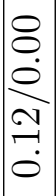 & 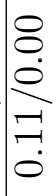 & $\begin{array}{l}8 \\
0 \\
0 \\
0 \\
0 \\
0 \\
0\end{array}$ & $\begin{array}{l}8 \\
0 \\
0 \\
20 \\
0 \\
0 \\
0\end{array}$ & $\frac{8}{0}$ & $\frac{8}{a}$ & 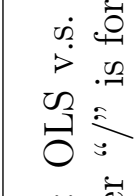 \\
\hline$\stackrel{+}{\sim}$ & 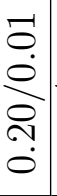 & $\begin{array}{c}8 \\
0 \\
0 \\
\\
\\
0\end{array}$ & 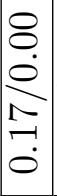 & 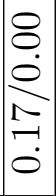 & 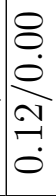 & $\begin{array}{l}8 \\
\dot{0} \\
0 \\
0 \\
0 \\
0\end{array}$ & $\begin{array}{l}8 \\
\dot{0} \\
0 \\
0 \\
0 \\
0\end{array}$ & $\mid \begin{array}{c}8 \\
0 \\
0 \\
8 \\
0 \\
0\end{array}$ & $:$ & 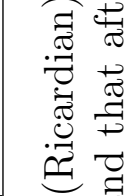 \\
\hline ? & $\begin{array}{c}\overrightarrow{0} \\
0 \\
0 \\
\\
\\
0 \\
0\end{array}$ & 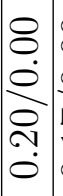 & \begin{tabular}{l}
8 \\
0 \\
0 \\
\\
\\
\hdashline \\
0
\end{tabular} & $\begin{array}{l}8 \\
\stackrel{0}{0} \\
\stackrel{+}{+} \\
\dot{1} \\
0\end{array}$ & $\begin{array}{l}8 \\
0 \\
0 \\
0 \\
0 \\
0 \\
0\end{array}$ & $\begin{array}{l}8 \\
0 \\
0 \\
0 \\
0 \\
0 \\
0\end{array}$ & 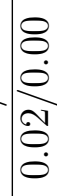 & $\frac{8}{8}$ & $\frac{\Xi}{a}$ & 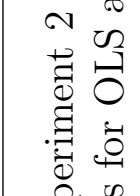 \\
\hline$\stackrel{\curvearrowright}{\sim}$ & 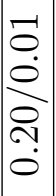 & $\mid$\begin{tabular}{c}
8 \\
0 \\
0 \\
0 \\
\hdashline \\
0 \\
0
\end{tabular} & $\mid \begin{array}{c}8 \\
0 \\
0 \\
120 \\
-1 \\
0 \\
0\end{array}$ & $\begin{array}{l}8 \\
0 \\
0 \\
\\
0 \\
0 \\
0\end{array}$ & $\begin{array}{l}8 \\
0 \\
0 \\
0 \\
0 \\
0\end{array}$ & $\begin{array}{l}8 \\
0 \\
0 \\
0 \\
0 \\
0\end{array}$ & $\begin{array}{l}8 \\
0 \\
0 \\
1 \\
0 \\
0 \\
0\end{array}$ & 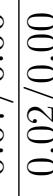 & $\frac{8}{a}$ & 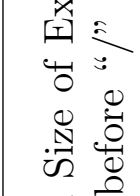 \\
\hline ב & 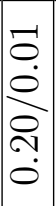 & $\left|\begin{array}{c}8 \\
0 \\
0 \\
0 \\
-2 \\
0 \\
0\end{array}\right|$ & $\begin{array}{c}8 \\
0 \\
0 \\
0 \\
0 \\
0 \\
0 \\
\end{array}$ & $\begin{array}{l}8 \\
0 \\
0 \\
\infty \\
\infty \\
0 \\
0 \\
0\end{array}$ & $\begin{array}{l}8 \\
0 \\
0 \\
0 \\
0 \\
0\end{array}$ & $\begin{array}{l}8 \\
0 \\
0 \\
0 \\
0 \\
0 \\
0\end{array}$ & $\begin{array}{l}\mathscr{8} \\
0 \\
0 \\
0 \\
0 \\
0 \\
0\end{array}$ & $\mid \begin{array}{c}0 \\
0 \\
0 \\
0 \\
0 \\
0\end{array}$ & : & 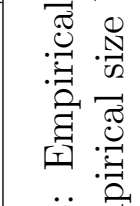 \\
\hline & 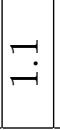 & $\stackrel{\sim}{\sim}$ & •ִּ & $\stackrel{+}{-}$ & - & & - & - & & $\begin{array}{cc}0 & 0 \\
0 & 0 \\
\tilde{\sigma} & \stackrel{G}{\epsilon}\end{array}$ \\
\hline
\end{tabular}




\section{References}

[1] Auerbach, A.J. (2003): "Fiscal Policy, Past and Present." Brookings Papers on Economic Activity, 2003:1, 75-138.

[2] Bohn, H. (1998): "The Behavior of U.S. Public Debt and Deficits." Quarterly Journal of Economics, 113(3), 869-902.

[3] Canova, F. (2007): "Methods for Applied Macroeconomic Research." Princeton University Press, Princeton, NJ.

[4] Cliff, M.T. (2003): "GMM and MINZ Program Libraries for MATLAB." Manuscript, Purdue University.

[5] Cochrane, J.H. (1998): "A Frictionless View of U.S. Inflation." NBER Macroeconomics Annual, 13, 323-384.

[6] Davig, T., Leeper, E.M. and Chung, H. (2007): "Monetary and Fiscal Policy Switching." Journal of Money, Credit and Banking, 39(4), 809-842.

[7] Galí, J. and Perotti, R. (2003): "Fiscal Policy and Monetary Integration in Europe." Economic Policy, 18(37), 533-572.

[8] Hamilton, J.D. (1994): "Time Series Analysis." Princeton University Press, Princeton, NJ.

[9] Leeper, E.M. (1991): "Equilibria Under 'Active' and 'Passive' Monetary and Fiscal Policies." Journal of Monetary Economics, 27(1), 129-147.

[10] (2005): "Macro Policy and Inflation: An Overview." Manuscript.

[11] Newey, W. and West, K. (1987): “A Simple Positive Semi-Definite, Heteroskedasticity and Autocorrelation Consistent Covariance Matrix." Econometrica, 55, 703-708. 
[12] Ruge-Murcia, F.J. (2007): "Methods to Estimate Dynamic Stochastic General Equilibrium Models." Journal of Economic Dynamics \& Control, 31(8), 25992636.

[13] Sims, C.A. (2001): "Solving Linear Rational Expectations Models." Journal of Computational Economics, 20(1-2), 1-20.

[14] Woodford, M. (1998): "Comment on John Cochrane, 'A Frictionless View of U.S. Inflation."” NBER Macroeconomics Annual, 13, 390-418.

[15] (2001): "Fiscal Requirements for Price Stability." Journal of Money, Credit and Banking, 33(3), 669-728. 